\title{
Does bystander behavior make a difference? How passive and active bystanders in the group moderate the effects of bullying exposure
}

Dol:

10.1037/ocp0000296

\section{Document Version}

Accepted author manuscript

Link to publication record in Manchester Research Explorer

Citation for published version (APA):

$\mathrm{Ng}$, K., Niven, K., \& Notelaers, G. (2021). Does bystander behavior make a difference? How passive and active bystanders in the group moderate the effects of bullying exposure. Journal of Occupational Health Psychology. https://doi.org/10.1037/ocp0000296

Published in:

Journal of Occupational Health Psychology

\section{Citing this paper}

Please note that where the full-text provided on Manchester Research Explorer is the Author Accepted Manuscript or Proof version this may differ from the final Published version. If citing, it is advised that you check and use the publisher's definitive version.

\section{General rights}

Copyright and moral rights for the publications made accessible in the Research Explorer are retained by the authors and/or other copyright owners and it is a condition of accessing publications that users recognise and abide by the legal requirements associated with these rights.

\section{Takedown policy}

If you believe that this document breaches copyright please refer to the University of Manchester's Takedown Procedures [http://man.ac.uk/04Y6Bo] or contact uml.scholarlycommunications@manchester.ac.uk providing relevant details, so we can investigate your claim.

\section{OPEN ACCESS}


Does bystander behavior make a difference? How passive and active bystanders in the group moderate the effects of bullying exposure

\author{
Kara $\mathrm{Ng}^{1}$, Karen Niven ${ }^{1}$, and Guy Notelaers ${ }^{2}$ \\ ${ }^{1}$ Alliance Manchester Business School, University of Manchester \\ ${ }^{2}$ Department of Psychosocial Science, University of Bergen
}

\title{
Author Note
}

Kara Ng 0000-0001-5547-6725

Karen Niven 0000-0002-6675-5532

Guy Notelaers 0000-0002-4482-0014

We have no known conflict of interest to disclose.

Correspondence concerning this article should be addressed to Kara $\mathrm{Ng}$, Alliance Manchester Business School, Booth Street West, Manchester, M15 6PB, UK, Email: kara.ng@manchester.ac.uk

The workplace bullying variable (S-NAQ) was used in a prior publication (Glambek, M., Einarsen, S. V., \& Notelaers, G. (2020). Workplace bullying as predicted by nonprototypicality, group identification and norms: a self-categorisation perspective. Work \& Stress, 34(3), 279-299. https://doi.org/10.1080/02678373.2020.1719554). The manuscript's ideas and model have not been disseminated prior to publication.

The study was funded by The Norwegian Research Council, Norges Forskningsråd (Grant/Award Number: 250127). 
(C) 2021, American Psychological Association. This paper is not the copy of record and may not exactly replicate the final, authoritative version of the article. Please do not copy or cite without authors' permission. The final article will be available, upon publication, via its DOI: 10.1037/ocp0000296 


\begin{abstract}
Workplace bullying has negative effects on targets' well-being. Researchers are increasingly aware that bullying occurs within social contexts and is often witnessed by others in the organization, such as bystanders. However, we know little about how bystanders' responses influence outcomes for those exposed to bullying. In this multilevel study, involving 572 employees within 55 work groups, we explore how bystanders' passive (e.g., inaction) and active constructive (e.g., defending the target) responses to bullying can affect targets' somatic symptoms and work engagement. Drawing from Job-Demands Resource theory, we propose that passive and active constructive bystanders can worsen or buffer bullying's effects on these well-being outcomes respectively. Specifically, we propose that passive bystanders can act as further demands for targets to cope with, leading to demand accumulation, while active constructive bystanders can act as resources. We found that exposure to workplace bullying was associated with somatic symptoms and low work engagement. The number of passive and active constructive bystanders in the target's work group moderated the relationship between exposure to bullying and engagement. In particular, with larger numbers of passive bystanders the negative relationship of bullying exposure with engagement strengthened. Conversely, with a higher number of active constructive bystanders, bullying's negative relationship with engagement was mitigated. However, there was no moderating effect for somatic symptoms. This study contributes as the first empirical test of whether bystander behavior shapes the consequences of bullying for targets and provides a novel, group-level perspective to the bullying bystander literature.
\end{abstract}

Keywords: Workplace bullying, bystander, engagement, somatic health 


\section{Does bystander behavior make a difference? How passive and active bystanders in the group moderate the effects of bullying exposure}

\section{Introduction}

Organizations are inherently social domains where employees interact during the course of their work. While many interactions are positive and can lead to beneficial outcomes, such as cohesion and belongingness (e.g., Spehar et al. 2016; Tekleab et al., 2009), there are also cases where interpersonal stressors emerge. One such stressor is workplace bullying, a social issue that researchers have identified as associated with many negative individual- and organizational-level consequences (Hoel et al., 2020; Mikkelsen et al., 2020). In an emerging body of literature, researchers (e.g., Reich \& Hershcovis, 2015) have demonstrated the relevance of the social context when it comes to forms of workplace mistreatment, such as bullying. The idea is that bullying occurs within a social context and it is important to understand the role of group members who witness bullying (bystanders) in order to tackle it. In line with this developing literature, practitioners are beginning to adopt these ideas in the form of bullying bystander training, which typically seeks to educate potential bystanders, with a view to encouraging them to adopt behaviors that should support the well-being of targets of bullying (Niven et al., 2020; Scully \& Rowe, 2009).

To date, most research in this area has focused on describing bystanders' reactions to mistreatment, for example, conceptualizing different behavioral reactions to witnessing bullying (e.g., Paull et al., 2012), and trying to identify factors that affect which behavior bystanders adopt (e.g., Hershcovis et al., 2017). An assumption underlying both this research and the work of practitioners is that bystander responses will shape the experiences of targets. However, while effects of bystander behavior on targets of workplace bullying have been theorized (e.g., $\mathrm{Ng}$ et al., 2020), empirical evidence is surprisingly lacking. 
The present study aims to investigate how bystander behaviors, within the context of the work group, can shape the effects of bullying experiences on targets' well-being outcomes. We focus in particular on the well-being outcomes of somatic symptoms and work engagement, which are two focal outcomes of the theoretical model that we adopt in this research, the Job Demands Resources model (JD-R; Demerouti et al., 2001; Schaufeli \& Taris, 2014). Drawing on the JD-R model, we propose that workplace bullying is a demand (e.g., Hoprekstad et al., 2019) that can lead to negative consequences for employees' somatic symptoms and work engagement - and that the behaviors enacted by bystanders in the work group can influence the severity of those effects. Specifically, we propose that active constructive bystanders, who enact behaviors involving confrontation of the perpetrator or helping the target, act as resources. As such, when there is a greater number of active constructive bystanders in a target's work group, the relationship between exposure to bullying and engagement and somatic symptoms ought to be buffered. Conversely, passive bystanders, whose behaviors amount to "doing nothing", are conceptualized as a further demand that compounds the negative impact of bullying. Accordingly, when there is a greater number of passive bystanders in a target's work group, the negative effects of exposure to bullying and engagement and somatic symptoms ought to be intensified.

Our study contributes to the literature in several ways. First, we bring to attention to the important role bystanders can play in helping or worsening target experiences, a topic that has come into recent focus (e.g., Sprigg et al., 2019). Bystanders are not, as traditional research typically implies, exclusively passive agents, but can express a range of responses to influence the progression of bullying. This serves to reinforce the social nature of bullying and that it is a problem expanding beyond the target-perpetrator dyad.

Second, our study contributes to understanding of the JD-R model by exploring the cumulative effects of multiple demands at different levels of analysis. While empirical 
research on the JD-R model has typically focused on the employee-level of analysis, Bakker and Demerouti (2017) have called for researchers to consider the group context in which employees work. Moreover, whereas research typically focuses on the Demand x Resource interaction, these scholars also called for extending the theory by further understanding Demand x Demand interactions, as demands rarely exist in isolation (Bakker \& Demerouti, 2017). Here, we examine how the relationship between the demand of bullying and wellbeing outcomes can be moderated by two distinctive responses at the level of the work group: active constructive bystander behaviors (a resource) and passive bystander behaviors (a demand).

\section{Workplace bullying}

Workplace bullying is defined as "harassing, offending, or socially excluding someone or negatively affecting someone's work" (S. Einarsen et al., 2011, p. 22), in a persistent manner over an extended period (Rai \& Agarwal, 2018). A wide range of behaviors can constitute as bullying, including spreading gossip about the target, ignoring or excluding the target, and playing practical jokes at the target's expense (Notelaers et al., 2019).

Bullying shares many core features with other forms of workplace mistreatment (Hershcovis, 2011), but its latter two definitional characteristics, persistence and long duration, differentiate workplace bullying from other negative interpersonal acts such as workplace violence or aggression. It is also a dynamic process, which scholars describe as a "vicious circle": as time goes on, mistreatment towards the target become more frequent and severe, often affecting work and relationships outside the perpetrator-target dyad, further isolating the victim (K. Einarsen, et al., 2020; Leymann, 1996; Ng et al., 2020; Zapf et al., 2011). 
Workplace bullying can have adverse effects on targets, which is unsurprising, given that repeated and sustained exposure to bullying behaviors can wear down one's resolve (Hogh et al., 2011). Studies suggest that targets experience various indicators of psychological strain, including somatic health complaints, chronic fatigue, low self-esteem, and irritability (Hogh et al., 2011; Moayed et al., 2006). When compared with non-bullied groups, Vartia's (2001) study on the Finnish workforce found that targets reported higher general stress and mental stress reactions, while also being over five times as likely to regularly use sleep-inducing drugs. Bullying is also related to cardiovascular disease; studies indicate that individuals who are bullied are twice as likely to suffer from cardiovascular illness compared to non-bullied samples (e.g., Xu et al., 2019). In terms of cognitive wellbeing, researchers have also found that bullying negatively affects employees' work engagement, by frustrating basic needs (Rodríguez-Muñoz et al., 2009; Trépanier et al., 2015) and violating their psychological contracts (S. Einarsen et al., 2016; Park \& Ono, 2017; Rai \& Agarwal, 2017).

Moving beyond the individual target, workplace bullying can also harm the wider organization, particularly if such behaviors are endemic and normalized. Absenteeism, lower commitment, presenteeism, and turnover have been associated with workplace bullying, which can have indirect effects on performance (e.g., Hoel et al., 2011). All these outcomes may lead to financial consequences, particularly if litigation is involved; for example, Kline and Lewis (2019) estimate that bullying and harassment in England's National Health Service costs the taxpayer approximately $£ 2.3$ billion (approximately US $\$ 3$ billion) annually.

Though many organizations and societies recognize the ill-effects of bullying for employees and their organizations and have committed to initiatives intending to prevent bullying (Hershcovis et al., 2015; Zapf \& Vartia, 2020), it is unfortunately still a relatively common occurrence. Reviews and meta-analyses suggest that prevalence levels may range 
from $11.8 \%$ to $20 \%$, depending on methodologies used and contexts studied (e.g., Nielsen et al., 2010; Zapf et al., 2011). Thus, it is clear workplace bullying is a serious issue that must be better understood.

\section{Workplace bullying bystanders}

Traditional research has taken a narrow focus to understanding workplace bullying, focusing on target experiences, where the "epicenter" of harm occurs (e.g., Nielsen et al., 2008; Plopa et al., 2017; Tuckey \& Neall, 2014). In the nascent research considering bystanders as part of the workplace bullying process, an important early focus was on how bystanders may experience outcomes congruent to targets, such as stress and psychological harm, albeit to a lesser extent (e.g., D’Cruz \& Noronha, 2011; Totterdell et al., 2012; Vartia, 2001). However, more recently scholars have offered a more nuanced conceptualization of bystanders as independent agents who can influence the workplace bullying situation $(\mathrm{Ng}$ et al., 2020). Under this perspective, the focus moves away from how bystanders themselves are affected by witnessing bullying and towards seeking to understand how they respond behaviorally.

In particular, researchers note that bystanders may enact a range of behavioral responses to workplace bullying, such as intervening to try to stop bullying, doing nothing, or supporting the perpetrator and even ostracizing targets (Coyne et al., 2019; Mulder et al., 2016). These insights build on work in areas adjacent to workplace bullying, such as school bullying, sexual harassment, and other workplace mistreatment literatures, which have recognized a range of bystander responses for some time (e.g., Bowes-Sperry \& O’LearyKelly, 2005; Salmivalli, 1999; Twemlow et al., 2004). In describing the range of responses in workplace bullying, we draw from Paull and colleagues' (2012) typology of bystander 
behaviors, which proposes that bystanders can respond in ways that are either active or passive and constructive or destructive.

Passive bystander behaviors are those that do not address the bullying. While passive constructive bystanders recognize that the bullying is harmful and may feel sympathetic, they ultimately do nothing; in contrast, passive destructive bystanders simply ignore the bullying altogether. Although these two types of responses diverge in the sense that the bystander's perceptions of the bullying and the attention paid to it are different, the actual behavior enacted, from an external perspective (such as that of the target or perpetrator), is the same, i.e., doing nothing. Thus, for the purposes of the present study, wherein we focus on how bystanders' responses shape the effects of bullying for targets, both response types can be amalgamated into a single category of passive bystander behavior. Passive responses are commonplace when witnessing negative social situations more broadly, as established in the body of social psychology research documenting the so-called "bystander effect" (Darley \& Latané, 1968). Workplace bullying research has likewise shown substantial evidence that witnesses behave in a seemingly passive manner (e.g., Rai \& Agarwal, 2017; van Heugten, 2011). Similarly, the literature on workplace sexual harassment documents the prevalence of passive responses; in a study of 198 sexual harassment cases in Australia, at least 132 (66\%) involved some kind of passive bystander response (McDonald et al., 2016).

In contrast, active behaviors are those that address the bullying, either constructively, through seeking to improve the situation for the target, or destructively, through seeking to worsen the situation for the target. Although destructive bystander behaviors have been discussed, e.g., in Omari’s (2010) study describing bystanders laughing in response to bullying behaviors, here, we focus on active constructive behaviors as they offer an avenue to aid interventions to reduce bullying's negative effects. For example, bystanders who enact active constructive responses are thought to play an important role in preventing incidents of 
conflict and violence from escalating (Lassiter et al., 2018), and evaluations of training in active constructive behavior in school bullying and college sexual violence show evidence of prevention of future victimization (e.g., Nickerson et al., 2014; Salmivalli et al., 2011). Active constructive behaviors have been documented in qualitative research on workplace bullying, such as van Heugten's $(2011 ; 2010)$ studies, where targets discussed how active constructive bystanders helped to maintain or boost their self-confidence. They are also widely endorsed in hypothetical vignette studies on workplace mistreatment (e.g., Hershcovis et al., 2017; Vranjes et al., in press) as well as being observed in experimental field studies of customer incivility (Hershcovis et al., 2017).

Though research offers promising evidence on the multifaceted nature of bystander responses, our empirical understanding of the impact that different bystander behaviors have on targets, and our theoretical understanding of why these effects occur, is relatively lacking. In this present study, we draw on the JD-R model (Demerouti et al., 2001) to conceptualize bullying as a demand for targets. We propose that bystander behavior can act as either a resource or a demand to ameliorate or exacerbate the harmful effects of bullying on target well-being, depending on the specific type of behavior that is enacted. The following section will discuss the JD-R Model and contextualize workplace bullying and bystander behavior within its framework.

\section{The JD-R Model}

Researchers have long sought to understand the processes behind occupational wellbeing, including what factors enhance, or worsen, well-being outcomes for employees. The JD-R Model is a popular theory in this vein, used by researchers and practitioners to investigate the causes of well-being in organizational settings (Bakker \& Demerouti, 2014). 
The JD-R model proposes that across all occupations there are two key sets of factors that influence employees' well-being: Job demands and job resources. On one hand, job demands are the physical, social, or organizational aspects of a job that require employees to exert mental or physical effort (Demerouti et al., 2001). On the other hand, job resources are physical, social, or organizational aspects of a job that help employees to achieve desired goals or stimulate personal development at work (Bakker et al., 2005). The original formulation of the JD-R (Demerouti et al., 2001) held that job demands cause psychological ill-health in the form of burnout - a state characterized by feelings of exhaustion, ineffectiveness and cynicism (Maslach et al., 2001) - due to the sustained mental or physical exertion they incur, while resources serve to buffer the ill-effects of demands because they enable workers to cope with demands.

The revised JD-R (Schaufeli \& Bakker, 2004) extended the range of outcomes of demands and resources in two key ways. First, it explained that because burnout can lead to health problems, the impact of demands and resources on burnout would in turn lead to health impairments, such as somatic symptoms. Somatic symptoms describe the physical conditions, such as sleep problems and gastrointestinal issues, that appear alongside, or are a result of, underlying psychological issues like burnout (e.g., Hakanen et al., 2008; Schat \& Kelloway, 2003; Simon et al., 1999). Second, the revised JD-R explicitly includes work engagement as a key outcome. Work engagement, which is sometimes considered the antithesis of burnout, refers to a state of vigor, dedication, and absorption an employee feels in relation to work (Schaufeli \& Bakker, 2010). While initially conceptualized as an exclusive outcome of job resources (such that greater resources would directly enhance engagement; Schaufeli \& Bakker, 2004), recent theoretical and empirical work has shown that engagement is also negatively linked to job demands and hence resources buffer the negative relationship between demands and engagement. For example, Schaufeli and Taris (2014) note that "an 
additional assumption should be made that job demands ... are negatively related to work engagement" (p. 56) and refer to a meta-analysis supporting this assumption (Crawford et al., 2010; p. 52).

Researchers have found strong evidence for the core propositions of JD-R - that resources buffer the ill-effects of demands - which can have useful practical applications for organizations who wish to improve employee outcomes and address demands that are difficult to remove completely from jobs. This could be especially salient in cases of bullying, where prevalence rates remain stubbornly high (e.g., Nielsen et al., 2010; Zapf et al., 2011), in part because perpetrators may not be fired or relocated from their original work group and current interventions are not always effective in completely removing bullying behaviors (Escartin, 2016) ${ }^{1}$.

While scholars have looked at a variety of demands in relation to the JD-R model, issues remain that may help further our knowledge of how different elements inherent within a job or work environment can influence well-being. This study explores two such issues. First, we propose that workplace bullying can be positioned as a demand in the JD-R model. This proposition contrasts with the majority of research, which has conceptualized bullying as an outcome of job demands (e.g., Baillien et al., 2011), drawing from the "work environment hypothesis" (Leymann, 1996), which proposes that bullying emerges when work characteristics are unfavorable or stressful (S. Einarsen et al., 2011; Leymann, 1993). We argue that bullying can also be viewed as a demand in and of itself. This is because exposure to bullying necessitates the exertion of high levels of cognitive and emotional effort to process and deal with the situation; it is a demanding experience. Our shift towards framing

\footnotetext{
${ }^{1}$ In Escartin's (2016) review of intervention studies, 3 of the 8 studies analysed reported no change in bullying post-intervention. Moreover, one study, by Chipps and McRury (2012), noted that bullying increased after the intervention, with the researchers hypothesizing that the training may simply have made targets more aware of what constituted as bullying.
} 
bullying as a demand is consistent with the original JD-R theorists, who positioned interpersonal conflicts as a demand within their model (Schaufeli \& Bakker, 2004), as well as the work of some recent scholars (e.g., Hoprekstad et al., 2019; Rhee et al., 2017).

Second, we wish to further explore the interactive effect of multiple demands within the context of the JD-R model. It is only recently that key theorists have remarked upon a knowledge gap in understanding how demands interact with each other (Bakker \& Demerouti, 2017) and, to our knowledge, very few papers so far explore this topic. Van Woerkom and colleagues (2016) explain this "Demand x Demand" interaction, known as demand accumulation, by drawing on conservation of resources theory (COR; Hobfoll, 1989). COR theory suggests that people seek to conserve their current resources. To cope with demands, individuals must use their available resources, which, if depleted, can lead to greater strain and lower work engagement. When there are more demands to face, individuals expend even more resources to cope, leading to a "resource loss spiral" (Rodríguez-Muñoz et al., 2020). The demand accumulation argument therefore acknowledges that demands can be further exacerbated by additional demands, leading to even poorer well-being. Van Woerkom and colleagues' (2016) study offers empirical support to this extension of theory, as they found that an interaction between work and emotional demands predicted higher absenteeism (an indicator of strain) among Dutch workers.

\section{The moderating role of bystander behaviors}

JD-R researchers frequently recognize the relevance of social aspects of the work environment as either demands (e.g., conflict) or resources (e.g., social support). Moreover, workplace bullying researchers have long theorized that the social environment around the target may affect bullying outcomes (S. Einarsen et al., 2011). Here, we explain how the behavior of bystanders in one's work group can be understood either as a resource that 
enables coping and therefore buffers the effects of the demand of bullying on relevant outcomes, or as a further demand that triggers a resource loss spiral and therefore exacerbates the negative impact of bullying on targets. In particular, we argue that the number of bystanders in a group exhibiting a particular type of behavior may be indicative of norms, such that a higher number indicates stronger norms encouraging said behavior. We focus on the outcomes of somatic health and work engagement, which, as described above, are key states that have been implicated in the JD-R model in its various iterations (e.g., Schaufeli \& Taris, 2014). Please refer to Figure 1 for our study's model.

\section{INSERT FIGURE 1 ABOUT HERE}

Active constructive bystanders. Drawing from Paull and colleagues' (2012) typology, active constructive behaviors reflect "typical deontic-driven responses of bystanders as saviors" (Ng et al., 2020, p. 1723), who will typically defend the target, intervene directly in the bullying situation, or seek to defuse it. The idea of such responses as being deontic comes from deontic justice theory, which assumes that people will intervene in unethical situations simply because they see moral violations occurring and regardless of consequences (Cropanzano et al., 2001). That is, people will intervene because it is the "right thing to do". Previous conceptual work on workplace mistreatment has elaborated on such perspectives, arguing that witnessing mistreatment elicits intuitions of moral violation, which lead to an emotional response and to justice-based appraisals, and in turn to active constructive behaviors (O’Reilly \& Aquino, 2011).

Targets of bullying who are aware of active constructive bystander responses are likely to interpret these as supportive, as such behaviors indicate overt condemnation of 
bullying behaviors. The behavior of active constructive bystanders demonstrates that they are allied with the target, who may rely on them to provide extra resources, such as support. For example, a target who sees their colleagues speak out against the perpetrator will know that other people have registered the mistreatment (the intuition of moral violation and subsequent moral anger, according to O'Reilly and Aquino's, 2011, model). Even in cases where targets are unaware of active constructive bystander responses (e.g., if the bystander were to confront the perpetrator at a later point in time when the target was not present), these may serve as a resource that mitigates the demand of bullying, if such responses actually reduce the bullying itself. As Kim (2019) notes, active constructive bystanders can "protect" targets from the worst effects of bullying by disrupting harmful power dynamics and decreasing the frequency or intensity of negative acts. These scenarios suggest that the existence of such bystanders in one's work group may help to buffer the negative effects of bullying as targets have further resources atop their own finite ones. This is likely to be especially true within work groups where the number of active constructive bystanders is high, as this indicates the presence of more powerful norms that support targets and seek to halt the course of the bullying process, which is suggestive of a safe social climate for targets (Kim, 2019; $\mathrm{Ng}$ et al., 2020).

As targets can draw upon their active constructive bystanding colleagues as resources, they will have more energy to deal with their mistreatment, particularly in situations where there is a higher number of active constructive bystanders. In this case, targets have an additional, contingent resource to soften bullying's negative impact on their somatic health and work engagement. Therefore, we hypothesize:

Hypothesis 1: The number of active constructive bystanders within the workgroup will moderate the negative relationship between bullying exposure and work engagement, such that the relationship will weaken as the number of active constructive bystanders in the target's work group increases. 
Hypothesis 2: The number of active constructive bystanders within the workgroup will moderate the positive relationship between bullying exposure and somatic symptoms, such that the relationship will weaken as the number of active constructive bystanders in the target's work group increases.

Passive bystanders. Passive bystander responses echo those described in Darley and Latané's (1968) “bystander effect”, where observers do not offer to help targets and thereby appear apathetic from the external perspective (e.g., that of the target or perpetrator of bullying). There are several explanations as to why bystanders may enact this behavior. Following Ng and colleagues' (2020) model, bystanders who appraise that the situation is not serious enough to warrant intervention, or who believe the target "deserves" the mistreatment somehow, or who do not believe they are sufficiently efficacious to intervene, are likely to respond passively to bullying. In O'Reilly and Aquino's (2011) model, bystanders who have appraise themselves as having low power (who therefore may fear retaliation) and an avoidance motivation are also likely to "do nothing". Other researchers have implicated ambiguity as a major driver for passive bystander behavior, including in the original bystander apathy studies (e.g., Darley \& Latané, 1968) and influential theories on bystander behavior in sexual harassment (Bowes-Sperry \& O’Leary-Kelly, 2005).

Targets who perceive passive responses from those around them may feel they have no one to turn, creating a further demand in addition to bullying. For example, interviewed targets discussed how colleagues who "withdrew" (i.e., did nothing) made them feel more isolated and vulnerable (Lewis \& Orford, 2005), in part because targets appraise neutral (i.e., passive) bystanders negatively, as silently supporting the perpetrator (D’Cruz \& Noronha, 2011; S. Einarsen et al., 2011). In some cases, targets reported that their colleagues' inaction was "worse than the bullying itself" (Paull et al. 2012, p. 357). Targets may feel betrayed by their colleagues, particularly if they had positive relationships prior, and may wonder if their 
colleagues think the bullying is justified. Even neutral or passive behaviors may be interpreted by targets as tacitly supporting the perpetrator, which can lead to further distress (Leymann, 1996). In interviews conducted by D’Cruz and colleagues (2016), targets even reported feeling like passive bystanders may have "enjoyed" observing the mistreatment. Targets may even begin to doubt the reality of their own victimization, questioning whether or not they are being bullied at all or have misinterpreted the situation. As such, targets are likely to expend energy trying to understand their colleagues' responses ("Was I just being too sensitive?" or “Do my colleagues not care?”).

Targets in such situations therefore not only need to draw upon their resources to cope with the bullying itself, but also require additional resources to understand and contend with their colleagues' inaction. As such, the passive responses of colleagues in one's work group can be seen as a further demand that exacerbates the original demand of the bullying (i.e., demand accumulation; van Woerkom et al., 2016). A greater number of passive bystanders in a group may indicate stronger norms that condone or diminish bullying behaviors. Thus, the negative impact of bullying is further worsened by an additional, contingent factor, much like the resource loss spiral noted by past researchers (Rodríguez-Muñoz et al., 2020). Accordingly, we hypothesize that:

Hypothesis 3: The number of passive bystanders will moderate the negative relationship between bullying exposure and work engagement, such that the relationship will strengthen as the number of passive bystanders in the target's work group increases.

Hypothesis 4: The number of passive bystanders will moderate the positive relationship between bullying exposure and somatic symptoms, such that the relationship will strengthen as the number of passive bystanders in the target's work group increases.

\section{Method}




\section{Procedure and sample}

The study was conducted among employees at a large Dutch university as part of an undesirable behavior assessment commissioned by the organization. While the present study focuses on workplace bullying, work engagement, somatic symptoms and the behavior of bullying bystanders, the organization requested inclusion of questions on other negative behaviors, such as sexual harassment, which are not reported in this paper. The ethics of the study's protocol was ratified by the Norwegian Centre for Research Data.

Data were collected through a cross-sectional, online survey, which was sent to 4836 employees. Of these, 1257 employees (26\%), who worked across 238 workgroups, completed the questionnaire. Given our focus on bystander behaviors within the context of work groups, we only selected work groups where six or more participants completed the questionnaire. This threshold was selected with both statistical and theoretical considerations in mind. Theoretically, bullying is often conceptualized as a less common phenomenon (e.g., Zapf et al., 2020), and with our interest in the influence of the behavior of bystanders in the group, we wanted a minimum group size large enough to feasibly capture bullying and bystander behavior. Statistically, to estimate a random slopes model for analysis, there must be a sufficient within-level observations to ascertain variation in the exogenous and endogenous variables. Due to bullying's low endorsement, there may be a lack of variation if there are only one or two observations per group, hence the need for a higher group threshold. Setting six in particular as the threshold allowed us to maintain over 50 higher level units, which is a recommended minimum as lower numbers at the higher level can lead to biased estimates of standard errors (e.g., Maas \& Hox, 2005). We retained 55 workgroups comprising of 572 respondents as our final sample. 
Our final sample had an average age of 42 years $(\mathrm{SD}=12.8)$, were majority female $(62 \%)$, and were nested in 55 teams with a mean size of 10.4 members $(\mathrm{SD}=4.37$; range $=6$ 24). Over half (55\%) held academic positions in the university, with the rest holding administrative support roles. In comparison analyses, we found that participants in our final sample were more likely to be women $(\chi(2)=29.34, p<.001)$ and in administrative positions $(\chi(101)=338.17, p<.001)$ compared to total population in the university $(\mathrm{n}=4836)$. However, there were no significant differences between the two groups in age $(t(4835=$ $-.441, p>.05)$

\section{Measures}

Due to the multinational nature of the university, measures were applied in both English and Dutch. We used existing validated measures and their translations for the workplace bullying, engagement, and somatic symptoms measures. The university's translation services provided forward and backward translation services to ensure accuracy in translations for the bystander behavior items, which did not have validated translations.

Exposure to workplace bullying $(\alpha=.88)$. Participants' exposure to bullying was measured using the Short-Negative Acts Questionnaire (S-NAQ; Notelaers et al., 2019), adapted from the original Negative Acts Questionnaire (S. Einarsen et al., 2009). This 9-item scale lists common bullying behaviors, such as "Devaluing of your work and efforts" and "Social exclusion from co-workers or work group activities". Participants indicated the frequency that they experienced these behaviors in the past six months by answering a 5point Likert-type scale ( $1=$ 'Never'; 5 = 'Daily').

Active and passive bystanders in the group. To measure the number of active and passive bystanders of workplace bullying in the group, we first identified participants among the sample who were possible bystanders. Past work suggests that researchers should be 
careful not to conflate target and bystander experiences (i.e., bystanders who are also targets themselves) when studying workplace bullying as this may be a significant confounder in examining bullying's effects (e.g., Nielsen \& Einarsen, 2013; Salin \& Notelaers, 2018; Sprigg et al., 2019). To address these potential confounding issues, we excluded anyone who had been exposed to any degree of bullying-type behavior from answering questions regarding their bystander experiences. Accordingly, only participants who reported "never" experiencing all items of the S-NAQ were considered as possible bystanders for the purposes of this study as they could be confidently classed as "non-targets".

We asked the "non-target" participants to indicate the number of people in their team who were subjected to the bullying behaviors listed in the S-NAQ. Those who reported one or more members of the team as having been subjected to the S-NAQ behaviors were assumed to either be witnesses to bullying or perpetrators, given their awareness of bullying in the group. They were therefore routed to a survey item asking how they responded to the negative behaviors by choosing one of four options. The first two options represented the two types of bystander responses we were interested in studying: the passive bystander response ("I kept out; in other words, I remained passive") and the active constructive bystander response ("I tried to prevent this type of behavior or even stop it"). The remaining two options were included to account for the possibility of those aware of the bullying behaviors having enacted either an active destructive bystander response ("Someone else initiated this type of behavior and I went along with it"), or even being the perpetrator themselves (“I initiated this type of behavior").

For participants who did not identify with any of those response types, we included a fifth option, which was an open text box for participants to input other responses. As responses were in both Dutch and English, Dutch responses were translated and coded by a member of the research team who was fluent in both languages. The translated responses 
were then independently coded by another member of the research team. Responses were coded into the original categories, with examples from Paull and colleagues' (2012) typology used as criteria for coding. The interrater agreement was $96.78 \%$, with all but one of the responses being agreed on. The single case of disagreement was resolved through discussion among the research team.

In total, 179 of the 572 participants were routed to complete the bystander behavior item. Of these, 135 participants reported one or more people in the workgroup having been exposed to bullying-type behaviors. Following coding of the open-text responses, 1 participant was deemed not to be a witness. As no participants reported being a perpetrator of the bullying-type behaviors, this means that, in total, 134 out of the 179 participants $(74.9 \%)$ who had not been personally exposed to any bullying-type behaviors had witnessed some degree of bullying in their workgroup. Of these bystanders, 56 participants (41.8\%) reported an active constructive response and $78(58.2 \%)$ reported a passive response. None reported an active destructive response.

Somatic symptoms $(\alpha=.79)$. The survey measured somatic symptoms with the 10 item Flemish Work Monitor (Bourdeaud'hui et al., 2004). Participants were asked to indicate whether they had experienced certain health complaints in the past two weeks using a dichotomous response scale ("No" = 1, "Yes" = 2), with mean scores calculated across the item set. Sample somatic complaints include "trouble falling asleep" or headache".

Work engagement $(\alpha=.94)$. Work engagement was measured using the shortened 9item Utrecht Work Engagement Scale (UWES-9; Schaufeli et al., 2006), which was adapted from the original 17-item UWES (Schaufeli et al., 2002). Participants responded to each item on a 7-point Likert-type scale ( 1 = "Never", 7 = "Every day"). Sample items include "I feel happy when I am working intensely" and “At my work, I feel bursting with energy". 
Control variables. We controlled for age and gender in our analyses, as previous research has shown these factors to relate to somatic health outcomes and engagement (Camgoz et al., 2016; Eriksen et al., 1999; Mastenbroek et al., 2014). Our analysis also controlled for organizational position (academic vs. administrative role) due to the differences in job characteristics and expectations of both positions.

\section{Analysis}

Preliminary analyses were conducted using IBM SPSS 25. Analyses were conducted using hierarchical linear modelling as this would account for the dependent nature of measurements at the lower level (Hox, 2002). That is, because our participants were nested within workgroups, variance in their well-being might be accounted for both at the individual and group level of analyses. A confirmatory factor analysis (CFA) was run to check that items we measured conformed to the expected factor structure. ${ }^{2}$ Study hypotheses were then tested using MLwiN v. 3.02 using stepwise estimation of different models (Charlton et al., 2017). ${ }^{3}$ Both independent (workplace bullying) and dependent (somatic symptoms and engagement) variables were individual-level variables, while the moderators (number of active constructive and passive bystanders in the group) were at the group level (Level 2).

We repeated the following analysis procedure for each outcome variable. We first built an intercept-only model (Model 0) and then another model with the covariates added (Model 1), then added workplace bullying as a predictor (Model 2; Rasbash et al., 2009). We next built a random intercept-slope model (Model 3), which allows the relationship between

\footnotetext{
${ }^{2}$ We first ran a multilevel CFA to acknowledge the nested nature of our data; however, this did not converge, likely due to the large number of no within-cluster variation variables. We therefore report a within-level CFA.

${ }^{3}$ We considered the use of alternative statistical programs that would allow for multiple outcomes within the same model; however, because we found a lack of intercept variance for somatic symptoms in the first step of our analyses (see below, Model 0), a multivariate analysis approach was not warranted.
} 
workplace bullying and the outcome in question to vary across work groups. We then began exploration of our moderators. We added the main effects of both moderators in turn (Model 4 for number of active constructive bystanders and Model 5 for number of passive bystanders). Then, in order to test the moderation hypotheses, we added cross-level interactions separately (Model 6 for passive bystanders*bullying and Model 7 active constructive bystanders*bullying), which controlled for any between-level interactions that may exist in the data (Enders \& Tofighi, 2007; Hofmann \& Gavin, 1998).

We tested the multivariate significance of effects in each step by computing the increase in model fit compared with the previous step. The increase in model fit is represented by the decrease of the $\Delta-2 \log$ likelihood statistic (-2LL), which follows a $\chi 2$ distribution and describes the model's deviance, or unexplained variance, which should decrease as we build our model. We also calculated pseudo $\mathrm{R}^{2}$ values after each step, focusing on the within and the between part of the variances explained each time a variable was added into the model (Snijders \& Bosker, 1994). Pseudo $\mathrm{R}^{2}$ values are similar to $\mathrm{R}^{2}$ values describe, usually in percentages, how much the current model explains the data, and can be used to show improvement of fit as variables are added to the model. As our moderators were between-group variables (i.e., they represented the number of active/passive bystanders in a work group), we would expect them to explain between group variance in our outcome variables.

Our primary criteria for accepting a hypothesis were to establish significant variance terms at the between level, and to observe a significant cross-level interaction term (e.g., number of passive bystanders in a group*bullying) at $p<.05$, with the interaction taking the hypothesized form. To explore the form of our moderation effects, slopes were plotted using Preacher and colleagues' (2006) hierarchical linear modelling tools. Interactions were all plotted at +/- 1 standard deviation of the moderator (Bauer \& Curran, 2005). 


\section{Results}

\section{Preliminary analyses}

The CFA, in which we specified a three-factor model (exposure to bullying, somatic health, work engagement), showed good fit, $\chi 2(347)=1127$, RMSEA $=0.06(0.06 ; 0.07)$, $\mathrm{CFI}=0.98, \mathrm{TLI}=0.98, \mathrm{SRMR}=0.07$, which was superior to the fit of a two-factor model in which we combined somatic health and work engagement as a single factor, $\chi 2(349)=2131$, $p<.001$. Table 1 presents the means, standard deviations, and correlations of all study constructs and covariates of gender, age, and organizational position. There was a significant, moderate correlation between work engagement and somatic symptoms $(r=-.41, p<.05)$, indicating that the two constructs are negatively related to one another, but not highly so, indicating satisfactory discriminant validity. Participants reported that the average amount of exposure to bullying was relatively low over the past six months $(\mathrm{M}=1.33$; $\mathrm{SD}=.52)$.

\section{INSERT TABLE 1 ABOUT HERE}

We tested the effects of exposure to bullying on both outcomes in Model 2 of each of the models we built up. As can be seen in Tables 2 and 3, respectively, for the engagement and somatic symptoms models, exposure to bullying was a significant predictor of both outcomes. Exposure to bullying was negatively related to work engagement, explaining $13.8 \%$ of the variance in the model $(\mathrm{B}=-.88, p<.001)$, and positively related to somatic symptoms, explaining $16.8 \%$ of variance $(\mathrm{B}=.18, p<.001)$. The following sections will discuss the results of hypothesis testing, in which we examine the moderating effects of active constructive and passive bystander responses on the above relationships. 


\section{INSERT TABLES 2 AND 3 ABOUT HERE}

\section{Moderating effect of active constructive bystander responses}

Hypotheses 1 and 2 proposed that active constructive bystander responses will moderate the negative relationship of bullying with work engagement $(\mathrm{H} 1)$ and the positive relationship of bullying with somatic symptoms $(\mathrm{H} 2)$, such that both relationships will weaken as the number of active constructive bystanders increases in the target's work group. These predicted effects were tested in Model 7 of each of the models we built up (in Table 2 for engagement and Table 3 for somatic symptoms).

With respect to the outcome of work engagement, when we added the active constructive bystander*bullying interaction in Model 7 (final column of Table 2), the between level slope and intercept variance in work engagement were both significant. The cross-level interaction observed for the number of active constructive bystanders in the group on the relationship between bullying and engagement was also significant $(\mathrm{B}=.16, p<.05)$. There was also a decrease in the Model's -2LL, indicating that addition of the interaction term improved model fit. ${ }^{4}$ Figure 2 illustrates the direction of the moderation at +1 and -1 SD the number of active constructive bystanders in the group, showing that as expected, targets who had more active constructive bystanders in their workgroup showed a weaker negative

\footnotetext{
${ }^{4}$ The improvement in fit was not quite significant $(\Delta-2 \mathrm{LL}=-3.31, p=.07)$, most likely because here we were testing additional improvement in fit over and above the cross-level interaction of passive bystanders in the group, as reported below.
} 
association between exposure to bullying and work engagement than those with fewer active constructive bystanders. On this basis, we accept Hypothesis 1.

However, for the outcome of somatic symptoms, when we added the active constructive bystander*bullying interaction in Model 7 (final column of Table 3), there was no variance explained at the between level, and there was no significant cross-level interaction for the number of active constructive bystanders in the group on the relationship between bullying and somatic symptoms $(\mathrm{B}=.003, p>.05)$. As such, Hypothesis 2 was not supported.

\section{INSERT FIGURE 2 ABOUT HERE}

\section{Moderating effect of passive bystander responses}

Hypotheses 3 and 4 predicted that passive bystander responses will moderate the negative relationship between bullying and work engagement $(\mathrm{H} 3)$ and the positive relationship between bullying and somatic symptoms (H4), such that both relationships will strengthen as the number of passive bystanders increases in the target's work group. These predicted effects were tested in Model 6 of each of the models we built up (in Tables 2 and 3).

With respect to the outcome of work engagement, when we added the passive bystander*bullying interaction in Model 6 (penultimate column of Table 2), the between level slope and intercept variance in work engagement were both significant. Furthermore, a significant cross-level interaction was observed for the number of passive bystanders in the group on the relationship between bullying and engagement $(\mathrm{B}=-.28, p<.05)$. There was 
also a significant decrease in the model fit when the interaction term was added (change $=$ 4.67, $p<.05$ ), meaning that the addition led to a better model fit. Figure 3 illustrates the direction of the moderation, showing that, as expected, targets who had more passive bystanders in their workgroup showed a stronger negative association between exposure to bullying and work engagement than those with fewer passive bystanders. As such, Hypothesis 3 was supported.

Finally, for the outcome of somatic symptoms, when we added the passive bystander*bullying interaction in Model 6 (penultimate column of Table 3), there was no variance explained at the between level. Surprisingly, given this fact, we did observe a significant cross-level interaction for the number of passive bystanders in the group on the relationship between bullying and somatic symptoms $(\mathrm{B}=.04, p<.05)$. However, the lack of between group variance explained, alongside the increase in model deviance (indicating poorer fit in comparison to before the interaction term was added), suggests that this significant interaction term may be a spurious effect. Taking these sources of information together, we therefore reject Hypothesis 4.

\section{INSERT FIGURE 3 ABOUT HERE}

\section{Discussion}

In this study, we examined how different bystander responses can affect the work engagement and somatic symptoms of others in the work group who are exposed to workplace bullying. While previous research has largely established that experiencing workplace bullying leads to significantly poorer health and well-being outcomes (e.g., S. Einarsen et al., 2011), there has been substantially less research on how socio-contextual 
factors can affect this relationship. Moreover, research has largely minimized the role of bystanders in influencing this process, though conceptual work has argued that bystanders can enact a variety of behaviors beyond just passivity (e.g., Ng et al., 2020; O'Reilly \& Aquino, 2011; Paull et al., 2012).

Drawing from the JD-R theory, we framed workplace bullying as a demand whose negative effects can be modified based on the behavior of fellow group members who witness the occurrence of bullying. We expected that the number of active constructive bystanders (e.g., those who confront the perpetrator) or passive bystanders (e.g., those who do nothing) in the group would buffer or worsen the negative effects of bullying, respectively. We specifically argued that active constructive bystanders serve as a resource, providing more energy for targets to cope with mistreatment. Conversely, we framed passive bystanders as additional demands, as targets would need to expend further resources coping with and understanding why their colleagues seemingly ignored their suffering or unease. The latter hypothesis expands our understanding of how demands interact with each other, which has been largely overlooked in JD-R literature (Bakker \& Demerouti, 2017).

Consistent with our expectations, we found that the number of passive bystanders in a group exacerbated the negative relationship between exposure to bullying behaviors and targets' work engagement. These findings are consistent with qualitative research, where targets describe the differential effects colleagues' reactions have on their well-being. For example, Omari's (2007) interviews feature targets recalling how they were "left sitting open-mouthed, feeling embarrassed and ... probably more angry that not one of the other executives in the room acknowledged the [bullying]" (p. 99), indicating that colleagues' passivity increased unpleasant feelings associated with mistreatment. Targets may perceive such inaction as siding with the perpetrator as a "passive accomplice" (Namie \& LutgenSandvik, 2010, p. 344), who condones the negative acts or inadvertently empowers the 
perpetrator (Van Heugten, 2011). School psychologists echo these findings and report that bystanders who do nothing (i.e., a passive response) are likely to "contribute to the derogation of victims and the cycle of violence" (Padgett \& Notar, 2013, p. 35).

We further found that the number of active constructive bystanders in a work group attenuated the negative relationship between exposure to bullying behaviors and work engagement. While there has been little empirical work linking active constructive bystander responses to improving well-being outcomes in targets of workplace bullying, conceptual work often assumes that active constructive bystanders will have a positive effect on targets (e.g., Ng et al., 2020; Paull et al., 2020). Constructive responses are thought to help validate the target's experiences, which is important as targets try to make sense of subjective and troublingly uncertain behaviors (Volkema et al., 1996). They also can provide further resources to help targets to cope effectively and can even reduce further demands experienced. However, it is important to note that the harmful effects of passive bystanders were stronger on target engagement than the positive effect of active constructive bystander responses. This may highlight how persistently negative the effects of bullying can be, even with the presence of helpful resources (i.e., active constructive bystanders). The strength of passive bystanders' responses on work engagement is in line with previous qualitative work whereby targets describe colleagues' passivity as worse than the bullying itself (Paull et al., 2012).

The pattern of findings we observed did not extend to the outcome of targets' somatic symptoms, suggesting that bystanders may have a stronger influence over certain types of well-being than others. This indicates an important boundary to the potential for interventions focusing on bystander behavior; while the support of colleagues through active constructive bystander responses might encourage those exposed to bullying-type behaviors to maintain engagement in their work, it does not appear to eliminate the possibility of damage to 
workers' somatic health. A possible explanation for this is that the JD-R model frames somatic symptoms as a downstream consequence of burnout (Schaufeli \& Bakker, 2004), which we did not study in this research. Thus, perhaps it may take longer exposure to bullying to affect one's somatic symptoms or general health, via shorter-term changes in burnout (e.g., Hakanen \& Schaufeli, 2012; Innstrand et al., 2012). Future longitudinal research explicitly capturing burnout could test this possibility directly.

\section{Theoretical implications}

Our study makes key theoretical contributions to both workplace bullying and JD-R literatures. First, while there is emerging research on third parties in the mistreatment process, which has provided insights into bystanders' perspectives and actions, there has been little work understanding how these actions actually affect targets. Our study is the first, to our knowledge, to quantitatively examine how bystander behaviors within a group can shape target outcomes. This is an important contribution as it provides empirical support to conceptual work seeking to understand target and bystander experiences, which have typically looked at each agent in isolation of the other (e.g., $\mathrm{Ng}$ et al., 2020; Parzefall \& Salin, 2010). Moreover, the findings provide substance to research and practice that operates on the assumption that bystanders are key stakeholders in addressing the issue of workplace mistreatment (e.g., K. Einarsen et al., 2020; Niven et al., 2020).

Second, our study contributes to a greater understanding of how forms of mistreatment, such as bullying, operate within a group context, which is vital to address given that workplace mistreatment occurs within the inherently social domain of the organization. In bystander research, bystanders are often viewed as independent agents who react in some way to the behaviors witnessed within perpetrator-target dyads. Here, we provide a different 
perspective, recognizing that perpetrators, targets, and bystanders operate within work groups, and that the behavior of bystanders as a collective can shape targets' experiences.

Finally, our research sought to understand the interactive effects of demands at different levels, and their effects on well-being outcomes. While past research has mainly focused on how resources can mitigate the stress brought on by demands, recent literature has called for a greater understanding of how demands can worsen the effects of other demands (e.g., Bakker \& Demerouti, 2017; Van Woerkom et al., 2016). This study is one of the first to investigate how the influence of one interpersonal stressor, workplace mistreatment, on wellbeing can be worsened by the demand of passive bystander behavior. By exploring the "Demand x Demand" interaction, we can understand another dimension of how poor wellbeing develops at work.

\section{Practical implications}

Our study shows that active and passive bystander responses can influence the work engagement of those exposed to bullying-type behaviors. These findings provide support to recent calls that bystander behaviors should be included in future interventions, by fostering constructive responses and social support (K. Einarsen et al., 2020). In fact, bystanders may be the "missing link" in developing effective interventions, as previous research suggests that interventions, which typically have a narrower focus, such as on the target or targetperpetrator dyad, have shown very mixed results (Escartín, 2016).

Our findings therefore add weight to the development of more comprehensive interventions that consider bystanders' role in mistreatment and the role of the group context in shaping the outcomes of bullying behaviors. As bystander responses did not have a moderating effect on targets' somatic symptoms in this study, it is important to acknowledge that targets' physical health may still suffer when exposed to bullying behaviors. Thus, there 
might be a limit to how effective interventions targeting bystander behavior are with respect to somatic symptoms. However, as a counter to this, it could be argued that by promoting contexts where active constructive bystander behaviors are encouraged, interventions may shape group norms, such that bullying behaviors are recognized and are not tolerated. Over time, this may not just have an effect on buffering the negative effects of mistreatment but might also lessen the occurrence of mistreatment altogether (and thereby minimize damage to workers' health). In support of this assertion, an evaluation of training programs to encourage active constructive bystanders in college campus sexual violence found that interpersonal violence rates decreased $17 \%$ among students in the intervention group compared to the control group (Coker et al., 2016).

Interventions that incorporate bystanders may be particularly effective in stopping bullying early in its process, when negative behaviors are more similar to incivility, being generally less frequent, less severe, and more ambiguous (Leymann, 1996; Ng et al., 2020; Notelaers \& Van der Heijden, 2019), and when relevant group norms are not yet strongly established. With the introduction of strong group norms in the use of active constructive behavior in response to witnessed mistreatment, bullying may gradually be stopped early on, as suggested in Salmivalli and colleagues' (2011) work.

\section{Limitations and future research implications}

Our study has several limitations, which may be addressed in future research. One notable limitation was the cross-sectional nature of the study, which prevents us from making definitive causal conclusions on the ways in which our study variables were related. For example, it could be the case that those with poorer work engagement or greater somatic symptoms are more likely to be targeted with bullying behaviors rather than the reverse. However, it would be difficult to account for the patterns of moderation we observed in 
relation to the outcome of engagement with a reverse causal explanation, given that our moderator (bystander behavior) is assumed to be dependent on the occurrence of mistreatment. Nevertheless, the fact that we did not track participants longitudinally means that we could not observe whether the effects of bystander responses on the relationship between bullying behaviors and somatic symptoms are more likely to emerge over time.

Studying the relationships that we observed here longitudinally would not only be more informative about the causal direction of effects, but would also address questions about whether and how bystander behavior changes over time. Theoretical work suggests that because bullying is a dynamic phenomenon where behaviors change over time, the nature and frequency of bystander behavior might also change ( $\mathrm{Ng}$ et al., 2020). For example, initially helpful bystanders might “pull away” as bullying worsens (e.g., D’Cruz \& Noronha, 2011; Zapf et al., 2011). Repeated observations of bystander behavior would also allow researchers to distinguish between bystander behaviors that are frequently engaged, such that they likely represent group norms (e.g., members of the group challenge bullying-type behaviors most or all times that they are witnessed), versus one-off responses, which our current design precludes.

A second limitation is the possibility for biases, such as social desirability, affecting our findings, due to the reliance on self-report techniques, e.g., in reporting bystander behavior. Such biases may explain why no participants reported themselves as perpetrators, despite the clear presence of some bullying behaviors in the organization. An alternative possibility is that perpetrators of the bullying behaviors that were endorsed by the targets in our sample did not elect to participate in this research (which was voluntary), meaning that our sample may not have been representative. A third possibility to explain the lack of perpetrators, however, is that they did not regard themselves as "perpetrators", owing to the ambiguous intent of bullying ( $\mathrm{Ng}$ et al., 2020), meaning that the lack of self-described 
perpetrators in the sample may not automatically be due to such biases. Future research seeking to address this limitation could control for social desirability or use multisource data, such as asking targets to also report how others have responded when they were exposed to bullying behaviors, for validation purposes.

A further limitation is that our study design did not allow us to tell whether bystanders who reported intervening or not intervening when observing bullying did so in relation to the bullying experienced by targets in our sample. In theory, it could be the case that the events bystanders witnessed and the behaviors they responded with were in relation to targets who were not among our study participants. However, because, as we theorize, bystander behaviors contribute to group norms, it is possible that bystander behavior towards one group member might still shape the effects of bullying for a target to whom the behavior was not directed.

Because this study's survey was part of a wider questionnaire commissioned by a university, we included only shortened established scales to assess our constructs, such as the S-NAQ for bullying, which is a shortened version of the traditional NAQ-R (S. Einarsen et al., 2009). This was done to reduce the likelihood of attrition due to boredom or tiredness. However, the shortened measures used showed good internal reliability and derived from established, popular measures.

Although our study focused on two types of bystander responses, active constructive and passive, the Paull and colleagues (2012) typology that we followed to distinguish between bystander behaviors also identifies other bystander responses. Notably, Paull et al. (2012) distinguish between passive responses that are constructive versus destructive, and also identify that bystanders sometimes engage in active destructive responses, such as laughing or appearing to visibly enjoy the mistreatment (D’Cruz et al., 2016), which in the 
work group context might be seen to be part of a "mobbing" process (e.g., Einarsen et al., 2011). There may also be more fine-grained distinctions between behaviors that fall within particular categories within the over-arching typology we adopt. For example, Paull et al. (2012) themselves acknowledge different types of active constructive behaviors, including "defending", "intervening", "sympathizing" and "defusing", which differ according to targets' likely awareness of the behavior, among other factors. Future research exploring the effects of a broader range of behaviors might therefore provide greater insight into the more differentiated effects of bystander behavior on target outcomes, for example, helping to identify which types of active constructive behaviors are most helpful in mitigating ill-effects of bullying.

Future studies might also wish to incorporate targets as potential bystanders of bullying. In our research, in order to avoid confounding effects (see, e.g., Nielsen \& Einarsen, 2013; Salin \& Notelaers, 2018; Sprigg et al., 2019), we only studied the bystander behaviors of those who had not been exposed to any form of bullying behavior. However, the bystander behaviors of bullying targets could be a very interesting area to study, as these will also have the potential to influence outcomes for fellow targets. Such individuals might be more likely than non-targeted bystanders to engage in active constructive responses and/or less likely to be passive, due to empathy with fellow targets. Alternatively, they might be less likely to engage in active constructive responses and/or more likely to be passive, due to fear of drawing attention to themselves and being targeted again.

A further extension for future research will be to make a more explicit connection to coping. We suggest a link to coping in our theory development, in the sense that we anticipate that active constructive bystander responses will serve as resources for targets that aid their coping with the demand of bullying, whereas passive responses will require additional coping efforts from targets and thus serve as demands. It may therefore be useful 
to study whether different bystander responses influence targets' perceptions of and efforts towards coping, in order to substantiate this implied mechanism. Similarly, explicitly capturing the possible resources provided by active constructive responses (e.g., social support), which aid perceptions of coping, would help to elaborate on the mechanisms underlying the relationships observed here.

\section{Conclusion}

Workplace bullying is a harmful social issue that has negative implications for those who are exposed. Scholars have recently called for more work on how bystander responses can influence the way in which workplace bullying affects targets. In establishing that the presence of greater numbers of active constructive and passive bystanders in a work group shapes the relationship between exposure to bullying-type behaviors and targets' work engagement, our study addresses these calls. Our study contributes to our understanding of how socio-contextual factors influence the experiences of targets of workplace bullying and how demands interact with each other to worsen engagement. 


\section{References}

Baillien, E., Rodriguez-Muñoz, A., Van den Broeck, A., \& De Witte, H. (2011). Do demands and resources affect target's and perpetrators' reports of workplace bullying? A twowave cross-lagged study. Work \& Stress, 25(2), 128-146. https://doi.org/10.1080/02678373.2011.591600

Bakker, A. B., \& Demerouti, E. (2014). Job Demands-Resources Theory. In P. Y. Chen \& C. L. Cooper (Eds.), Work and Wellbeing: Wellbeing: A Complete Reference Guide (1st ed. (3), pp. 37-64). Wiley Blackwell.

Bakker, A. B., \& Demerouti, E. (2017). Job demands-resources theory: taking stock and looking forward. Journal of Occupational Health Psychology, 22(3), 273-285. https://doi.org/10.1037/ocp0000056

Bakker, A. B., \& Schaufeli, W. (2015, January 21). Work Engagement. In Wiley Encyclopedia of Management. Wiley \& Sons. https://doi.org/10.1002/9781118785317.weom110009

Bakker, A. B., Demerouti, E., \& Euwema, M. C. (2005). Job resources buffer the impact of job demands on burnout. Journal of Occupational Health Psychology, 10(2), 170-180. https://doi.org/10.1037/1076-8998.10.2.170

Bauer, D. J., \& Curran, P. J. (2005). Probing interactions in fixed and multilevel regression: Inferential and graphical techniques. Multivariate Behavioral Research, 40(3), 373400. https://doi.org/10.1207/s15327906mbr4003_5

Bourdeaud'hui, R., Janssens, F., \& Vanderhaege, S. (2004). Informatiedossier, Nulmeting Vlaamse Werkbaarheidsmonitor. htps://www.serv.be/sites/default/files/documenten/pdfpublicaties/1338.pdf

Bowes-Sperry, L., \& O'Leary-Kelly, A. M. (2005). To act or not to act: The dilemma faced by sexual harassment observers. Academy of Management Review, 30(2), 288-306 https://doi.org/10.5465/amr.2005.16387886

Camgoz, S. M., Ekmekci, O. T., Karapinar, P. B., \& Guler, B. K. (2016). Job insecurity and turnover intentions: Gender differences and the mediating role of work engagement. Sex Roles, 75(11-12), 583-598. https://doi.org/10.1007/s11199-016-0595-0

Charlton, C., Rasbash, J., Browne, W. J., Healy, M., \& Cameron, B. (2017). MLwiN Version 3.02. University of Bristol.

Chipps, E. M., \& McRury, M. (2012). The development of an educational intervention to address workplace bullying: A pilot study. Journal for Nurses in Professional Development, 28(3), 94-98. https://doi.org/10.1097/NND.0b013e31825514bb

Coker, A. L., Bush, H. M., Fisher, B. S., Swan, S. C., Williams, C. M., Clear, E. R., \& DeGue, S. (2016). Multi-college bystander intervention evaluation for violence prevention. American Journal of Preventive Medicine, 50(3), 295-302. https://doi.org/10.1016/j.amepre.2015.08.034 
Coyne, I., Gopaul, A. M., Campbell, M., Pankász, A., Garland, R., \& Cousans, F. (2019). Bystander responses to bullying at work: The role of mode, type and relationship to target. Journal of Business Ethics, 157(3), 813-827. https://doi.org/10.1007/s10551$\underline{017-3692-2}$

Cropanzano, R., Byrne, Z. S., Bobocel, D. R., \& Rupp, D. E. (2001). Moral virtues, fairness heuristics, social entities, and other denizens of organizational justice. Journal of Vocational Behavior, 58(2), 164-209. https://doi.org/10.1006/jvbe.2001.1791

Darley, J. M., \& Latané, B. (1968). Bystander intervention in emergencies: diffusion of responsibility. Journal of Personality and Social Psychology, 8(4), 377-383. https://doi.org/10.1037/h0025589

D'Cruz, P., \& Noronha, E. (2011). The limits to workplace friendship: Managerialist HRM and bystander behaviour in the context of workplace bullying. Employee Relations, 33(3), 269-288. https://doi.org/10.1108/01425451111121777

D'Cruz, P., Paull, M., Omari, M., \& Guneri-Cangarli, B. (2016). Target experiences of workplace bullying: Insights from Australia, India and Turkey. Employee Relations, 38(5), 805-823. https://doi.org/10.1108/ER-06-2015-0116

Demerouti, E., Bakker, A. B., Nachreiner, F., \& Schaufeli, W. B. (2001). The job demandsresources model of burnout. Journal of Applied Psychology, 86(3), 499. https://doi.org/10.1037/0021-9010.86.3.499

Einarsen, K., Nielsen, M. B., Hetland, J., Olsen, O. K., Zahlquist, L., Mikkelsen, E. G., Koløen, J. \& Einarsen, S. (2020). Outcomes of a proximal workplace intervention against workplace bullying and harassment: A protocol for a cluster randomized controlled trial among Norwegian industrial workers. Frontiers in psychology, 11, https://doi.org/10.3389/fpsyg.2020.02013

Einarsen, S., Hoel, H., \& Notelaers, G. (2009). Measuring exposure to bullying and harassment at work: Validity, factor structure and psychometric properties of the Negative Acts Questionnaire-Revised. Work \& Stress, 23(1), 24-44. https://doi.org/10.1080/02678370902815673

Einarsen, S., Hoel, H., Zapf, D., \& Cooper, C. (2011). The concept of bullying and harassment at work: The European tradition. In Einarsen, S., Hoel, H., Zapf, D., \& Cooper, C. L. (Eds.), Bullying and harassment in the workplace: Developments in theory, research, and practice (pp. 3-39). London, UK: CRC Press.

Enders, C. K., \& Tofighi, D. (2007). Centering predictor variables in cross-sectional multilevel models: A new look at an old issue. Psychological Methods, 12(2), 121-138. https://doi:10.1037/1082-989X.12.2.121

Eriksen, H. R., Ihlebæk, C., \& Ursin, H. (1999). A scoring system for subjective health complaints (SHC). Scandinavian Journal of Public Health, 27(1), 63-72. https://doi.org/10.1177\%2F14034948990270010401

Escartín, J. (2016). Insights into workplace bullying: psychosocial drivers and effective interventions. Psychology Research and Behavior Management, 9, 157-169. https://doi.org/10.2147/PRBM.S91211 
Hakanen, J. J., \& Schaufeli, W. B. (2012). Do burnout and work engagement predict depressive symptoms and life satisfaction? A three-wave seven-year prospective study. Journal of Affective Disorders, 141(2/3), 415-424. https://doi.org/10.1016/j.jad.2012.02.043

Hakanen, J. J., Schaufeli, W. B., \& Ahola, K. (2008). The Job Demands-Resources model: A three-year cross-lagged study of burnout, depression, commitment, and work engagement. Work \& Stress, 22(3), 224-241. https://doi.org/10.1080/02678370802379432

Hershcovis, M. S. (2011). “Incivility, social undermining, bullying... oh my!”: A call to reconcile constructs within workplace aggression research. Journal of Organizational Behavior, 32(3), 499-519. https://doi.org/10.1002/job.689

Hershcovis, M. S., Neville, L., Reich, T. C., Christie, A. M., Cortina, L. M., \& Shan, J. V. (2017). Witnessing wrongdoing: The effects of observer power on incivility intervention in the workplace. Organizational Behavior and Human Decision Processes, 142, 45-57. https://doi.org/10.1016/j.obhdp.2017.07.006

Hershcovis, M. S., Reich, T. C., \& Niven, K. (2015). Workplace bullying: Causes, consequences, and intervention strategies. Society for Industrial and Organizational Psychology.

Hobfoll, S. E. (1989). Conservation of resources: A new attempt at conceptualizing stress. American Psychologist, 44(3), 513-524. https://doi.org/10.1037/0003-066X.44.3.513

Hoel, H., Cooper, C. L., \& Einarsen, S. (2020). Organizational effects of workplace bullying. In Einarsen, S., Hoel, H., Zapf, D., \& Cooper, C. L. (Eds.), Bullying and harassment in the workplace: Developments in theory, research, and practice (pp. 209-234). London, UK: CRC Press.

Hoel, H., Sheehan, M. J., Cooper, C. L., Einarsen, S. (2011). Organisational Effects of Workplace Bullying. In Einarsen, S., Hoel, H., Zapf, D., \& Cooper, C. L. (Eds.), Bullying and harassment in the workplace: Developments in theory, research, and practice (pp. 129-143). CRC Publishing.

Hofmann, D. A., \& Gavin, M. B. (1998). Centering decisions in hierarchical linear models: Implications for research in organizations. Journal of Management, 24(5), 623-641. https://doi.org/10.1177\%2F014920639802400504

Hogh, A., Hoel, H., \& Carneiro, I. G. (2011a). Bullying and employee turnover among healthcare workers: a three-wave prospective study. Journal of Nursing Management, 19(6), 742-751. https://doi.org/10.1111/j.1365-2834.2011.01264.x

Hogh, A., Mikkelsen, E., \& Hansen, A. M. (2011b). Individual consequences of workplace bullying/mobbing. In Einarsen, S., Hoel, H., Zapf, D., \& Cooper, C. L. (Eds.), Bullying and harassment in the workplace: Developments in theory, research, and practice (pp. 107-122). CRC Publishing.

Holfeld, B. (2014). Perceptions and attributions of bystanders to cyber bullying. Computers in Human Behavior, 38, 1-7. https://doi.org/10.1016/j.chb.2014.05.012 
Hoprekstad, Ø. L., Hetland, J., Bakker, A. B., Olsen, O. K., Espevik, R., Wessel, M., \& Einarsen, S. V. (2019). How long does it last? Prior victimization from workplace bullying moderates the relationship between daily exposure to negative acts and subsequent depressed mood. European Journal of Work and Organizational Psychology, 28(2), 164-178. https://doi.org/10.1080/1359432X.2018.1564279

Hox, J. (2002). Multilevel analysis. Techniques and applications. Mahwah, NJ, US: Lawrence Erlbaum Associates Publishers.

Innstrand, S. T., Langballe, E. M., \& Falkum, E. (2012). A longitudinal study of the relationship between work engagement and symptoms of anxiety and depression. Stress and Health, 28(1), 1-10. https://doi.org/10.1002/smi.1395

Kim, K. (2020). Exploring the influence of workplace violence and bystander behaviour on patient safety in Korea: a pilot study. Journal of Nursing Management, 28(3), 735-743. https://doi.org/10.1111/jonm.12991

Kline, R., \& Lewis, D. (2019). The price of fear: estimating the financial cost of bullying and harassment to the NHS in England. Public Money \& Management, 39(3), 166-174. https://doi.org/10.1080/09540962.2018.1535044

Lewis, S. E., \& Orford, J. (2005). Women's experiences of workplace bullying: Changes in social relationships. Journal of Community \& Applied Social Psychology, 15(1), 29-47. https://doi.org/10.1002/casp.807

Leymann, H. (1993). Mobbing: Psychoterror am Arbeitsplatz und wie man sich dagegen wehren kann. Rowohlt.

Leymann, H. (1996). The content and development of mobbing at work. European Journal of Work and Organizational Psychology, 5(2), 165-184. https://doi.org/10.1080/13594329608414853

Li, X., McAllister, D. J., Ilies, R., \& Gloor, J. L. (2019). Schadenfreude: A counternormative observer response to workplace mistreatment. Academy of Management Review, 44(2), 360-376. https://doi.org/10.5465/amr.2016.0134

Lutgen-Sandvik, P., Tracy, S. J., \& Alberts, J. K. (2007). Burned by bullying in the American workplace: Prevalence, perception, degree and impact. Journal of Management Studies, 44(6), 837-862. https://doi.org/10.1111/j.1467-6486.2007.00715.x

Maas, C. J., \& Hox, J. J. (2005). Sufficient sample sizes for multilevel modeling. Methodology: European Journal of Research Methods for the Behavioral and Social Sciences, 1(3), 86-92. https://doi.org/10.1027/1614-1881.1.3.86

Maslach, C., Schaufeli, W. B., \& Leiter, M. P. (2001). Job burnout. Annual Review of Psychology, 52(1), 397-422. https://doi.org/10.1146/annurev.psych.52.1.397

Mastenbroek, N. J. J. M., Jaarsma, A. D. C., Demerouti, E., Muijtjens, A. M. M., Scherpbier, A. J. J. A., \& Van Beukelen, P. (2013). Burnout and engagement, and its predictors in young veterinary professionals: The influence of gender. Veterinary Record, 174(6), 144. https://doi.org/10.1136/vr.101762 
McKay, R., \& Fratzl, J. (2011). A cause of failure in addressing workplace bullying: Trauma and the employee. International Journal of Business and Social Science, 2(7), 13-27. https://doi.org/10.1.1.1038.2240

Mikkelsen, E. G., Hansen, Å. M., Persson, R., Byrgesen, M. F., \& Hogh, A. (2020). Individual consequences of being exposed to workplace bullying. In Einarsen, S., Hoel, H., Zapf, D., \& Cooper, C. L. (Eds.), Bullying and harassment in the workplace: Developments in theory, research, and practice (pp. 163-208). London, UK: CRC Press.

Mulder, R., Pouwelse, M., Lodewijkx, H., Bos, A. E., \& van Dam, K. (2016). Predictors of antisocial and prosocial behaviour of bystanders in workplace mobbing. Journal of Community \& Applied Social Psychology, 26(3), 207-220. https://doi.org/10.1002/casp.2244

Namie, G., \& Lutgen-Sandvik, P. E. (2010). Active and passive accomplices: The communal character of workplace bullying. International Journal of Communication, 4, 343-373. https://ijoc.org/index.php/ijoc/article/view/589

Nelson, J. K., Dunn, K. M., \& Paradies, Y. (2011). Bystander anti-racism: A review of the literature. Analyses of Social Issues and Public Policy, 11(1), 263-284. https://doi.org/10.1111/j.1530-2415.2011.01274.x

Ng, K., Niven, K., \& Hoel, H. (2020). 'I could help, but . . '’ A dynamic sensemaking model of workplace bullying bystanders. Human Relations, 73(12), 1718-1746. https://doi.org/10.1177\%2F0018726719884617

Nickerson, A. B., Aloe, A. M., Livingston, J. A., \& Feeley, T. H. (2014). Measurement of the bystander intervention model for bullying and sexual harassment. Journal of Adolescence, 37(4), 391-400. https://doi.org/10.1016/j.adolescence.2014.03.003

Nielsen, M. B., Matthiesen, S. B., \& Einarsen, S. (2008). Sense of coherence as a protective mechanism among targets of workplace bullying. Journal of Occupational Health Psychology, 13(2), 128-136. https://doi.org/10.1037/1076-8998.13.2.128

Nielsen, M. B., Matthiesen, S. B., \& Einarsen, S. (2010). The impact of methodological moderators on prevalence rates of workplace bullying. A meta-analysis. Journal of Occupational and Organizational Psychology, 83(4), 955-979. https://doi.org/10.1348/096317909X481256

Niven, K., Ng, K., \& Hoel, H. (2020). The bystanders of workplace bullying. In Einarsen, S., Hoel, H., Zapf, D., \& Cooper, C. L. (Eds.), Bullying and harassment in the workplace: Developments in theory, research, and practice (pp. 385-404). London, UK: CRC Press.

Notelaers, G., \& Van der Heijden, B. I. J. M. (2019). Construct Validity in Workplace Bullying and Harassment Research. In P. D’Cruz (Eds.), Handbooks of Workplace Bullying, Emotional Abuse and Harassment (1st ed. (1), pp. 2-44). Springer Nature. https://doi.org/10.1007/978-981-13-0134-6_11\#DOI 
Notelaers, G., Van Der Heijden, B. I., Hoel, H., \& Einarsen, S. (2018). Measuring bullying at work with the short-negative acts questionnaire: Identification of targets and criterion validity. Work and Stress, 33(1), 58-75. https://doi.org/10.1080/02678373.2018.1457736

Omari, M. (2007). Towards dignity and respect: An exploration of the nature, causes and consequences of workplace bullying. VDM Verlag Dr. Mueller E.K.

Omari, M. (2010). Towards dignity and respect at work: An exploration of work behaviours in a professional environment. https://www.lawsocietywa.asn.au/wpcontent/uploads/2015/10/Towards-Dignity-Respect-Work.pdf

O'Reilly, J., \& Aquino, K. (2011). A model of third parties' morally motivated responses to mistreatment in organizations. Academy of Management Review, 36(3), 526-543. https://doi.org/10.5465/amr.2009.0311

Padgett, S., \& Notar, C. E. (2013). Bystanders Are the Key to Stopping Bullying. Universal Journal of Educational Research, 1(2), 33-41. https://doi.org/10.13189/ujer.2013.010201

Pap, Z., Vîrgă, D., Notelaers, G. \& Maricuțoiu, L. (2020). A multilevel model of job insecurity and engagement. Journal of Managerial Psychology, 35(7/8), 529-541. https://doi.org/10.1108/JMP-02-2020-0089

Park, J. H., \& Ono, M. (2017). Effects of workplace bullying on work engagement and health: The mediating role of job insecurity. The International Journal of Human Resource Management, 28(22), 3202-3225. https://doi.org/10.1080/09585192.2016.1155164

Parzefall, M. R., \& Salin, D. M. (2010). Perceptions of and reactions to workplace bullying: A social exchange perspective. Human Relations, 63(6), 761-780. https://doi.org/10.1177\%2F0018726709345043

Paull, M., Omari, M. and Standen, P. (2012) When is a bystander not a bystander? A typology of the roles of bystanders in workplace bullying. Asia Pacific Journal of Human Resources, 50(3), 315-366. https://doi.org/10.1111/j.1744-7941.2012.00027.x

Paull, M., Omari, M., D'Cruz, P., \& Güneri Çangarli, B. (2020). Bystanders in workplace bullying: working university students' perspectives on action versus inaction. Asia Pacific Journal of Human Resources, 58(3), 313-334. https://doi.org/10.1111/1744$\underline{7941.12216}$

Plopa, M., Plopa, W., \& Skuzińska, A. (2017). Bullying at work, personality and subjective well-being. Journal of Occupational Health Psychology, 22(1), 19-27. https://doi.org/10.1037/a0040320

Polanin, J. R., Espelage, D. L., \& Pigott, T. D. (2012). A meta-analysis of school-based bullying prevention programs' effects on bystander intervention behavior. School Psychology Review, 41(1), 47-65. https://doi.org/10.1080/02796015.2012.12087375

Preacher, K. J., Curran, P. J., \& Bauer, D. J. (2006). Computational tools for probing interactions in multiple linear regression, multilevel modeling, and latent curve 
analysis. Journal of Educational and Behavioral Statistics, 31(4), 437-448. https://doi.org/10.3102\%2F10769986031004437

Rai, A., \& Agarwal, U. A. (2017). Linking workplace bullying and work engagement: the mediating role of psychological contract violation. South Asian Journal of Human Resources Management, 4(1), 42-71. https://doi.org/10.1177\%2F2322093717704732

Rai, A., \& Agarwal, U. A. (2018). A review of literature on mediators and moderators of workplace bullying. Management Research Review, 47(7), 822-859. https://doi.org/10.1108/MRR-05-2016-0111

Rasbash, J., Steele, F., Browne, W. J., \& Goldstein, H. (2009). A User's guide to MLwiN version 2.10. Centre for Multilevel Modelling: University of Bristol.

Reich, T. C., \& Hershcovis, M. S. (2015). Observing workplace incivility. Journal of Applied Psychology, 100(1), 203-215. https://doi.org/10.1037/a0036464

Rhee, S. Y., Hur, W. M., \& Kim, M. (2017). The relationship of coworker incivility to job performance and the moderating role of self-efficacy and compassion at work: The Job Demands-Resources (JD-R) Approach. Journal of Business and Psychology, 32(6), 711-726. https://doi.org/10.1007/s10869-016-9469-2

Rodríguez-Muñoz, A., Baillien, E., De Witte, H., Moreno-Jiménez, B., \& Pastor, J. C. (2009). Cross-lagged relationships between workplace bullying, job satisfaction and engagement: Two longitudinal studies. Work \& Stress, 23(3), 225-243. https://doi.org/10.1080/02678370903227357

Rodríguez-Muñoz, A., Antino, M., Ruiz-Zorrilla, P., Sanz-Vergel, A., \& Bakker, A. B. (2020). Short-term trajectories of workplace bullying and its impact on strain: A latent class growth modeling approach. Journal of Occupational Health Psychology, 25(5), 345-356. https://doi.org/10.1037/ocp0000232

Salin, D., \& Notelaers, G. (2020). The effects of workplace bullying on witnesses: violation of the psychological contract as an explanatory mechanism? The International Journal of Human Resource Management, 31(18), 2319-2339. https://doi.org/10.1080/09585192.2018.1443964

Salmivalli, C. (1999). Participant role approach to school bullying: Implications for interventions. Journal of Adolescence, 22(4), 453-459. https://doi.org/10.1006/jado.1999.0239

Salmivalli, C., Voeten, M., \& Poskiparta, E. (2011). Bystanders matter: Associations between reinforcing, defending, and the frequency of bullying behavior in classrooms. Journal of Clinical Child \& Adolescent Psychology, 40(5), 668-676. https://doi.org/10.1080/15374416.2011.597090

Schat, A. C., \& Kelloway, E. K. (2003). Reducing the adverse consequences of workplace aggression and violence: the buffering effects of organizational support. Journal of Occupational Health Psychology, 8(2), 110-122. https://doi.org/10.1037/1076$\underline{8998.8 .2 .110}$ 
Schaufeli, W. B., Salanova, M., González-Romá, V., \& Bakker, A. B. (2002). The measurement of engagement and burnout: A two sample confirmatory factor analytic approach. Journal of Happiness Studies, 3(1), 71-92. https://doi.org/10.1023/A:1015630930326

Schaufeli, W. B., \& Bakker, A. B. (2010). Defining and measuring work engagement: Bringing clarity to the concept. In Bakker., A., \& Leiter, M. P. (Eds.), Work engagement: A handbook of essential theory and research (12th ed., pp. 10-24). Psychology Press. https://doi.org/10.4324/9780203853047

Schaufeli, W. B., \& Taris, T. W. (2014). A critical review of the job demands-resources model: Implications for improving work and health. In Bauer, G. F., \& Hämmig, O. (Eds.) Bridging occupational, organizational and public health (pp. 43-68). Springer, Dordrecht. https://doi.org/10.1007/978-94-007-5640-3_4

Scully, M., \& Rowe, M. (2009). Bystander training within organizations. Journal of the International Ombudsman Association, 2(1), 89-95. https://www.bu.edu/fafc/files/2012/05/bystander.pdf

Simon, G. E., VonKorff, M., Piccinelli, M., Fullerton, C., \& Ormel, J. (1999). An international study of the relation between somatic symptoms and depression. New England Journal of Medicine, 341(18), 1329-1335. https://doi.org/10.1056/NEJM199910283411801

Snijders, T. A., \& Bosker, R. J. (1994). Modeled variance in two-level models. Sociological Methods \& Research, 22(3), 342-363. https://doi.org/10.1177\%2F0049124194022003004

Spehar, I., Forest, J., \& Stenseng, F. (2016). Passion for work, job satisfaction, and the mediating role of belongingness. Scandinavian Journal of Organizational Psychology, 8(1), 17-27. http://selfdeterminationtheory.org/wpcontent/uploads/2017/03/2016_Spehar_etal_2016_Scand_J_Org_Psych.pdf

Sprigg, C. A., Niven, K., Dawson, J., Farley, S., \& Armitage, C. J. (2019). Witnessing workplace bullying and employee well-being: A two-wave field study. Journal of Occupational Health Psychology, 24(2), 286. https://doi.org/10.1037/ocp0000137

Tekleab, A. G., Quigley, N. R., \& Tesluk, P. E. (2009). A longitudinal study of team conflict, conflict management, cohesion, and team effectiveness. Group \& Organization Management, 34(2), 170-205. https://doi.org/10.1177/1059601108331218

Totterdell, P., Hershcovis, M. S., Niven, K., Reich, T. C., \& Stride, C. (2012). Can employees be emotionally drained by witnessing unpleasant interactions between coworkers? A diary study of induced emotion regulation. Work \& Stress, 26(2), 112-129. https://doi.org/10.1080/02678373.2012.681153

Trépanier, S. G., Fernet, C., \& Austin, S. (2015). A longitudinal investigation of workplace bullying, basic need satisfaction, and employee functioning. Journal of Occupational Health Psychology, 20(1), 105-116. https://doi.org/10.1037/a0037726 
Tuckey, M. R., \& Neall, A. M. (2014). Workplace bullying erodes job and personal resources: Between-and within-person perspectives. Journal of Occupational Health Psychology, 19(4), 413-424. https://doi.org/10.1037/a0037728

Twemlow, S. W., Fonagy, P., \& Sacco, F. C. (2004). The role of the bystander in the social architecture of bullying and violence in schools and communities. Annals of the New York Academy of Sciences, 1036, 215-232. http://dx.doi.org/10.1196/annals.1330.014

Van Heugten, K. (2010). Bullying of social workers: Outcomes of a grounded study into impacts and interventions. British Journal of Social Work, 40(2), 638-655. https://doi.org/10.1093/bjsw/bcp003

Van Heugten, K. (2011). Theorizing active bystanders as change agents in workplace bullying of social workers. Families in Society, 92(2), 219-224. https://doi.org/10.1606/1044-3894.4090

Van Woerkom, M., Bakker, A. B., \& Nishii, L. H. (2016). Accumulative job demands and support for strength use: Fine-tuning the job demands-resources model using conservation of resources theory. Journal of Applied Psychology, 101(1), 141-150. https://doi.org/10.1037/apl0000033

Vartia, M. A. (2001). Consequences of workplace bullying with respect to the wellbeing of its targets and the observers of bullying. Scandinavian Journal of Work, Environment \& Health, 27(1), 63-69. https://doi.org/10.5271/sjweh.588

Volkema, R. J., Farquhar, K., \& Bergmann, T. J. (1996). Third-party sensemaking in interpersonal conflicts at work: A theoretical framework. Human Relations, 49(11), 1437-1454. https://doi.org/10.1177/001872679604901104

Vranjes, I., Lyubykh, Z. \&.Hershcovis, M. S. (in press). The role of observers in aggression. In K., Kelloway \& C., Cooper (Eds.). Research Agenda for Workplace Stress and Wellbeing. Edward Elgar Publishing

Xu, T., Magnusson Hanson, L. L., Lange, T., Starkopfc, L., Westerlund, H., Madsen, I. E., Rugulies, R., Pentti, J., Stenholm, S., Vahtera, J. Hansen, Å. M.., Virtanen, M., Kivimäki, M. \& Rod, N. H. (2019). Workplace bullying and workplace violence as risk factors for cardiovascular disease: a multi-cohort study. European Heart Journal, 40(14), 1124-1134. https://doi.org/10.1093/eurheartj/ehy683

Zapf, D., Escartin, J. Sheppa-Layani, M., Einarsen, S.V., Hoel, H., and Vartia, M. (2020). Empirical findings on Prevalence and Risk Groups of Bullying in the Workplace. In : Stale Einarsen, Helge Hoel, Dieter Zapf and Cary C Cooper (2020) Bullying and Harassment in the Workplace: Theory, Research and Practice. (pp. 105-162) Taylor and Francis

Zapf, D., \& Vartia, M. (2020). Prevention and treatment of workplace bullying: An overview. In Einarsen, S., Hoel, H., Zapf, D., \& Cooper, C. L. (Eds.), Bullying and harassment in the workplace: Developments in theory, research, and practice (pp. 457-496). CRC Press.

Zapf, D., Escartin, J., Einarsen, S., Hoel, H., \& Vartia, M. (2011). Empirical findings on prevalence and risk groups of bullying in the workplace. In Einarsen, S., Hoel, H., 
Zapf, D., \& Cooper, C. L. (Eds.), Bullying and harassment in the workplace: Developments in theory, research, and practice (pp. 75-105). CRC Publishing. 


\section{Table 1}

Descriptive statistics and correlations $(N=572)$

\begin{tabular}{|c|c|c|c|c|c|c|c|c|c|}
\hline Variable & Mean & SD & 1 & 2 & 3 & 4 & 5 & 6 & 7 \\
\hline 1. Gender & 1.36 & 0.48 & & & & & $-0.354^{*}$ & -0.221 & \\
\hline 2. Age & 42.00 & 12.18 & 0.044 & & & & $-0.345^{*}$ & -0.044 & \\
\hline $\begin{array}{l}\text { 4. Exposure to } \\
\text { bullying }\end{array}$ & 1.33 & 0.52 & -0.041 & -0.033 & 0.015 & & 0.141 & $0.702 *$ & \\
\hline $\begin{array}{l}\text { 6. Number of active } \\
\text { constructive } \\
\text { bystander responses } \\
\text { in the group ( } N=55 \\
\text { groups) }\end{array}$ & 1.67 & 1.68 & - & - & - & - & 0.086 & - & \\
\hline
\end{tabular}

Note. $* * p<.01 ; * p<.05$

Gender: 1 = Male; 2 = Female

Organizational position: 1 = Administrative 2 = Academic

The correlations in columns denoted with 5 and 6 are between-level correlations. 


\section{Table 2}

Results of multi-level regression analysis with unstandardized regression coefficients for engagement (and standard errors)

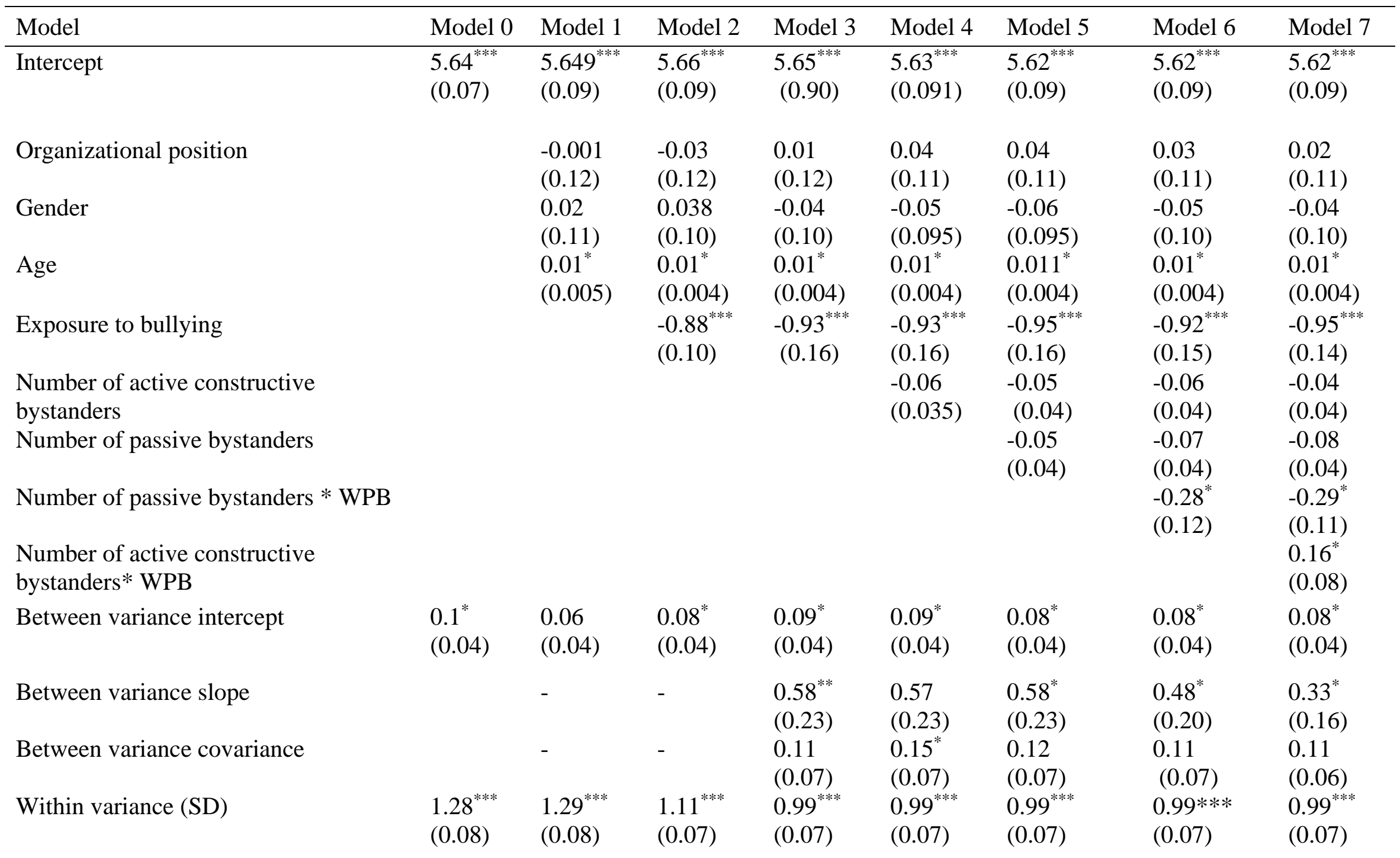




\begin{tabular}{|c|c|c|c|c|c|c|c|c|}
\hline Pseudo $\mathrm{R}^{2}$ between-level intercept (\%) & - & 38.14 & 21.65 & 10.31 & 10.31 & 18.45 & 20.62 & 20.62 \\
\hline$-2 * \log$ likelihood & 1711.19 & 1704.40 & 1630.71 & 1605.37 & 1602.54 & 1601.44 & 1596.77 & 1593.46 \\
\hline
\end{tabular}

$\Delta-2 * \log$ likelihood

$.70 \quad 73.69^{* * *} \quad 25.34^{* * *} \quad 2.83$

1.10

$4.67^{*}$

3.31

Note. $*^{* *} p<.001 ; * * p<.01 ; * p<.05$

WPB: Workplace bullying

Model 0 = Intercept-only model; Model $1=$ Intercept and covariates model; Model $2=$ Model with predictor (WPB); Model $3=$ Random intercept-slope model; Model 4 = Introduction of main effects of number of active constructive bystanders; Model $5=$ Introduction of main effects of number of passive bystanders; Model $6=$ Cross-level interactions for number of passive bystanders $*$ WPB; Model $7=$ Cross-level interactions for number of active constructive bystanders * WPB 


\section{Table 3}

Results of multi-level regression analysis with unstandardized regression coefficients for somatic symptoms (and standard errors)

\begin{tabular}{|c|c|c|c|c|c|c|c|c|}
\hline Model & Model 0 & Model 1 & Model 2 & Model 3 & Model 4 & Model 5 & Model 6 & Model 7 \\
\hline Intercept & $\begin{array}{l}1.30 * * * \\
(0.01)\end{array}$ & $\begin{array}{l}1.34 * * * \\
(0.02)\end{array}$ & $\begin{array}{l}1.33 * * * \\
(0.02)\end{array}$ & $\begin{array}{l}1.32 * * * \\
(0.02)\end{array}$ & $\begin{array}{l}1.34 * * * \\
(0.02)\end{array}$ & $\begin{array}{l}1.33^{* * * *} \\
(0.02)\end{array}$ & $\begin{array}{l}1.33 * * * \\
(0.02)\end{array}$ & $\begin{array}{l}1.33^{* * * *} \\
(0.02)\end{array}$ \\
\hline Organizational position & & $\begin{array}{l}-0.02 \\
(0.03)\end{array}$ & $\begin{array}{l}-0.02 \\
(0.03)\end{array}$ & $\begin{array}{l}-0.01 \\
(0.03)\end{array}$ & $\begin{array}{l}-0.02 \\
(0.03)\end{array}$ & $\begin{array}{l}-0.02 \\
(0.03)\end{array}$ & $\begin{array}{l}-0.02 \\
(0.03)\end{array}$ & $\begin{array}{l}-0.02 \\
(0.03)\end{array}$ \\
\hline Gender & & $\begin{array}{l}-0.06^{*} \\
(0.02)\end{array}$ & $\begin{array}{l}-0.05^{*} \\
(0.02)\end{array}$ & $\begin{array}{l}-0.05^{*} \\
(0.02)\end{array}$ & $\begin{array}{l}-0.05^{*} \\
(0.02)\end{array}$ & $\begin{array}{l}-0.05^{*} \\
(0.02)\end{array}$ & $\begin{array}{l}-0.05^{*} \\
(0.02)\end{array}$ & $\begin{array}{l}-0.05^{*} \\
(0.02)\end{array}$ \\
\hline Age & & $\begin{array}{l}-0.002 * \\
(0.001)\end{array}$ & $\begin{array}{l}-0.003 * \\
(0.001)\end{array}$ & $\begin{array}{l}-0.002 * \\
(0.001)\end{array}$ & $\begin{array}{l}-0.002 * \\
(0.001)\end{array}$ & $\begin{array}{l}-0.002 * \\
(0.001)\end{array}$ & $\begin{array}{l}-0.002 * \\
(0.001)\end{array}$ & $\begin{array}{l}-0.002 * \\
(0.001)\end{array}$ \\
\hline Exposure to bullying & & & $\begin{array}{l}.18 * * * \\
(0.02)\end{array}$ & $\begin{array}{l}.19 * * * \\
(0.03)\end{array}$ & $\begin{array}{l}.19 * * * \\
(0.03)\end{array}$ & $\begin{array}{l}.19 * * * \\
(0.03)\end{array}$ & $\begin{array}{l}.18 * * * \\
(0.02)\end{array}$ & $\begin{array}{l}.18 * * * \\
(0.02)\end{array}$ \\
\hline $\begin{array}{l}\text { Number of active constructive } \\
\text { bystanders }\end{array}$ & & & & & $\begin{array}{l}0.01 \\
(0.01)\end{array}$ & $\begin{array}{l}0.01 \\
(0.01)\end{array}$ & $\begin{array}{l}0.01 \\
(0.01)\end{array}$ & $\begin{array}{l}0.01 \\
(0.01)\end{array}$ \\
\hline Number of passive bystanders & & & & & & $\begin{array}{l}0.004 \\
(0.01)\end{array}$ & $\begin{array}{l}0.003 \\
(0.01)\end{array}$ & $\begin{array}{l}0.003 \\
(0.01)\end{array}$ \\
\hline $\begin{array}{l}\text { Number of passive bystanders * } \\
\text { WPB } \\
\text { Number of active constructive } \\
\text { bystanders } * \text { WPB }\end{array}$ & & & & & & & $\begin{array}{l}0.04^{*} \\
(0.02)\end{array}$ & $\begin{array}{l}0.04^{*} \\
(0.02) \\
0.003 \\
(0.01)\end{array}$ \\
\hline Between variance intercept & $\begin{array}{l}0.002 \\
(0.002)\end{array}$ & $\begin{array}{l}0.001 \\
(0.001)\end{array}$ & $\begin{array}{l}0.002 \\
(0.002)\end{array}$ & $\begin{array}{l}0.002 \\
(0.002)\end{array}$ & $\begin{array}{l}0.002 \\
(0.002)\end{array}$ & $\begin{array}{l}0.002 \\
(0.002)\end{array}$ & $\begin{array}{l}0.002 \\
(0.002)\end{array}$ & $\begin{array}{l}0.002 \\
(0.002)\end{array}$ \\
\hline Between variance slope & & - & - & $\begin{array}{l}0.004 \\
(0.01)\end{array}$ & $\begin{array}{l}0.004 \\
(0.01)\end{array}$ & $\begin{array}{l}0.004 \\
(0.01)\end{array}$ & $\begin{array}{l}0.000 \\
(0.003)\end{array}$ & $\begin{array}{l}0.000 \\
(0.003)\end{array}$ \\
\hline Between variance covariance & & - & - & $\begin{array}{l}-0.002 \\
(0.002)\end{array}$ & $\begin{array}{l}-0.002 \\
(0.002)\end{array}$ & $\begin{array}{l}-0.002 \\
(0.002)\end{array}$ & $\begin{array}{l}-0.002 \\
(0.002)\end{array}$ & $\begin{array}{l}-0.002 \\
(0.002)\end{array}$ \\
\hline Within variance & $\begin{array}{l}0.07 * * * \\
(0.004)\end{array}$ & $\begin{array}{l}0.07 * * * \\
(0.004)\end{array}$ & $\begin{array}{l}0.05 * * * \\
(0.004)\end{array}$ & $\begin{array}{l}0.06 * * * \\
(0.004)\end{array}$ & $\begin{array}{l}0.06 * * * \\
(0.004)\end{array}$ & $\begin{array}{l}0.06 * * * \\
(0.004)\end{array}$ & $\begin{array}{l}0.06 * * * \\
(0.004)\end{array}$ & $\begin{array}{l}0.06 * * * \\
(0.004)\end{array}$ \\
\hline
\end{tabular}




\begin{tabular}{|c|c|c|c|c|c|c|c|c|}
\hline $\begin{array}{l}\text { Pseudo } \mathrm{R}^{2} \text { between-level intercept } \\
(\%)\end{array}$ & - & 44.44 & $5.56 \%$ & $5.56 \%$ & $5.56 \%$ & $5.56 \%$ & $5.56 \%$ & $5.56 \%$ \\
\hline Pseudo $\mathrm{R}^{2}$ between-level slope (\%) & - & - & - & - & 0.00 & 0.00 & 100 & 100 \\
\hline Pseudo $\mathrm{R}^{2}$ within-level (\%) & - & 1.51 & 18.47 & 18.47 & 18.47 & 18.47 & 18.7 & 18.47 \\
\hline$-2 * \log$ likelihood & 78.79 & 67.31 & 5.68 & 3.63 & 2.04 & 1.79 & -1.85 & -1.85 \\
\hline$\Delta-2 * \log$ likelihood & & $11.48 * *$ & $1.64 * * *$ & 2.05 & 1.59 & 0.24 & -3.64 & 0.00 \\
\hline
\end{tabular}

$* * * p<.001 ; * * p<.01 ; * p<.05$

WPB: Workplace bullying

Model 0 = Intercept-only model; Model 1 = Intercept and covariates model; Model $2=$ Model with predictor (WPB); Model $3=$ Random intercept-slope model; Model 4 = Introduction of main effects of number of active constructive bystanders; Model $5=$ Introduction of main effects of number of passive bystanders; Model $6=$ Cross-level interactions for number of passive bystanders $*$ WPB; Model $7=$ Cross-level interactions for number of active constructive bystanders * WPB 
Figure 1

Theoretical model and hypotheses

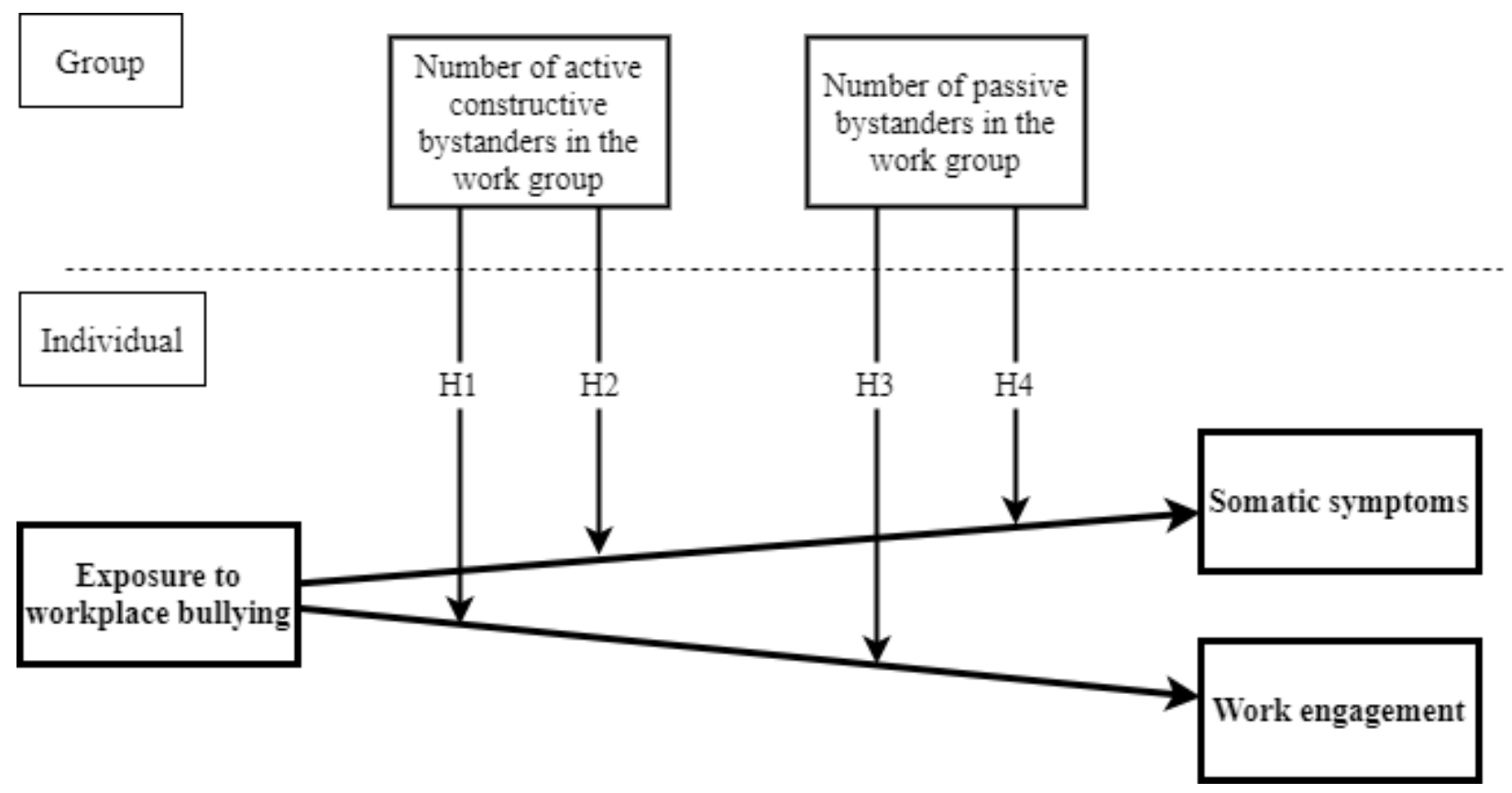




\section{Figure 2}

Cross-level interaction between number of active constructive bystanders in the group and exposure to bullying on targets' work engagement

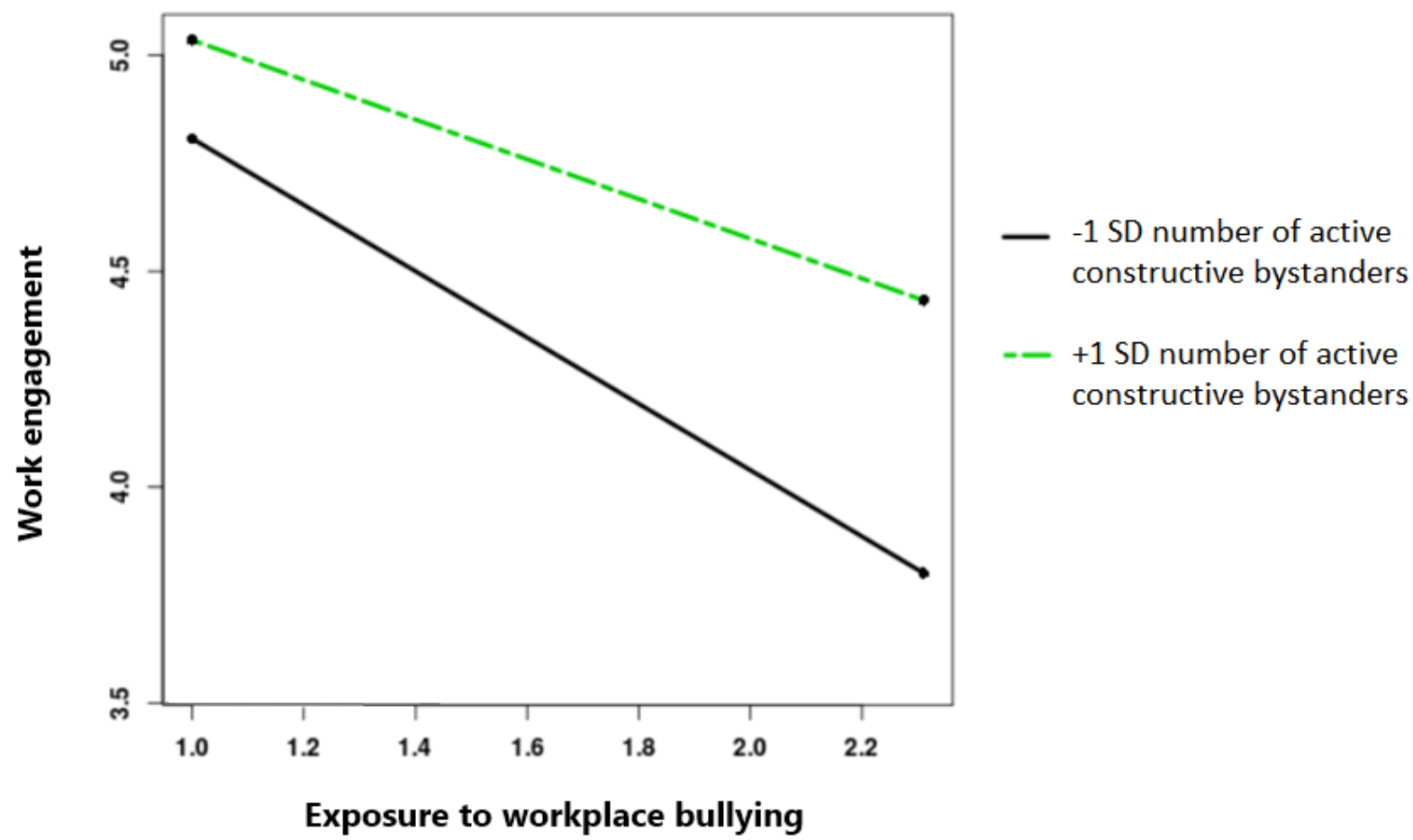




\section{Figure 3}

Cross-level interaction between number of passive bystanders in the group and exposure to bullying on targets' work engagement

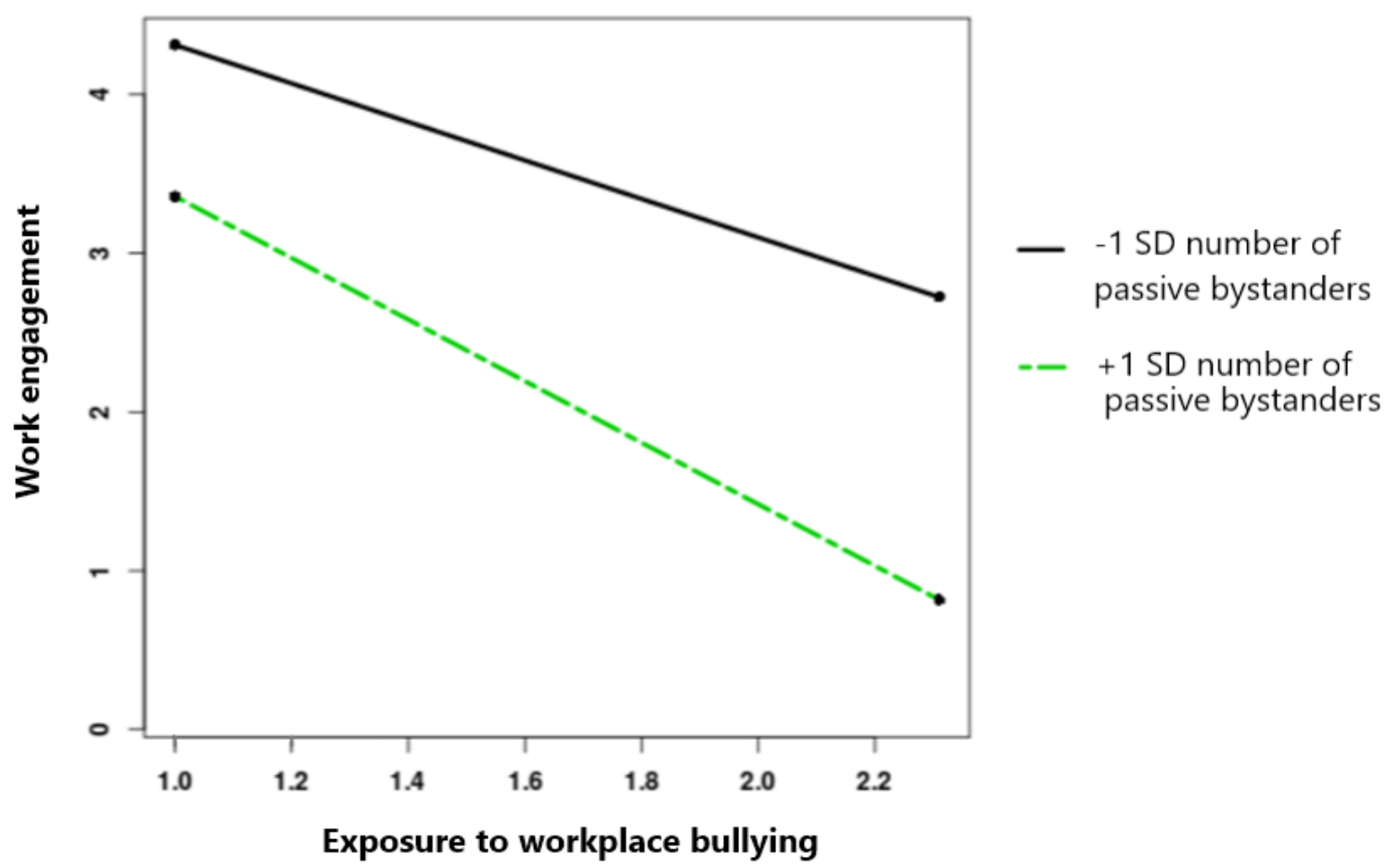

